\title{
El papel controversial del TEDH en la interpretación del Convenio de La Haya de 25 de octubre de 1980 sobre los Aspectos Civiles de la Sustracción Internacional de Menores: Especial referencia a los casos Neulinger y Shuruk c. Suiza y X c. Letonia
}

Fecha de recepción: 9 de febrero de 2019

Fecha de aprobación: 17 de noviembre de 2019

Doi: https://doi.org/10.12804/revistas.urosario.edu.co/acdi/a.8476

María Mayela Celis Aguilar*

Resumen: el presente artículo explora la reciente jurisprudencia del Tribunal Europeo de Derechos Humanos (TEDH) en materia de sustracción internacional de menores y reflexiona sobre su posible impacto en el

${ }^{*}$ Maestra en derecho por la Universidad de Nueva York (NYU). Anterior Oficial Legal Principal de la Conferencia de La Haya de Derecho Internacional Privado (HCCH) (www. hcch.net). Miembro de número de la Academia Mexicana de Derecho Internacional Privado y Comparado (AMEDIP). Doctoranda en el Programa de Doctorado en Derecho y Ciencias Sociales, Universidad Nacional de Educación a Distancia (UNED). El presente trabajo forma parte de la investigación que la autora está realizando en la UNED en el marco de la tesis doctoral que lleva por título (provisional): "El Convenio de La Haya sobre Sustracción de Menores: más de tres décadas de interpretación evolutiva”. Las opiniones reflejan únicamente el punto de vista de la autora y no el de la HCCH ni el de su Oficina Permanente. ORCID: https://orcid.org/0000-0002-2421-9520 Correo electrónico: mcelis23@alumno.uned.es

Para citar este artículo: Celis Aguilar, María Mayela. "El papel controversial del TEDH en la interpretación del Convenio de La Haya de 25 de octubre de 1980 sobre los Aspectos Civiles de la Sustracción Internacional de Menores: Especial referencia a los casos Neulingery Shuruk c. Suiza y X c. Letonia". Anuario Colombiano de Derecho Internacional (ACDI) 13, (2020): 209-249. http://doi.org/10.12804/revistas.urosario.edu.co/acdi/a.8476 
funcionamiento del Convenio de La Haya sobre Sustracción de Menores. Se hace especial referencia a la sentencia Neulingery Sburuk. c. Suiza dictada por la Gran Sala, así como a la "conmoción" que produjo en la comunidad jurídica. A continuación, se examina la sentencia $X$ c. Letonia misma que, tras el asunto Neulinger, ha sido la más sobresaliente emitida por la Gran Sala del TEDH. En particular, se analizan los razonamientos y fundamentos legales de dichas sentencias, poniendo de relieve tanto sus deficiencias como sus virtudes. Asimismo, se analizan sentencias recientes del TEDH y su consonancia o divergencia con los principios expuestos en $X c$. Letonia. Por último, y a la luz de los principios generales adoptados por el TEDH, se considera la dirección que este y los tribunales nacionales de los Estados parte deberían tomar.

Palabras clave: Tribunal Europeo de Derechos Humanos, sustracción de menores, interés superior del niño, Convenio de La Haya sobre los Aspectos Civiles de la Sustracción Internacional de Menores, Neulingery Shuruk c. Suiza, X c. Letonia.

The controversial role of the ECtHR in the interpretation of the Hague Convention of 25 October 1980 on the Civil Aspects of International Child Abduction, with special reference to Neulinger and Shuruk v. Switzerland and X v. Latvia

Abstract: The present article reflects on the recent case law of the European Court of Human Rights (ECtHR) on international child abduction and its potential impact on the operation of the Hague Child Abduction Convention. More specifically, it makes reference to the judgment given by the Grand Chamber in Neulinger and Shuruk. v. Switzerland, and the reaction it triggered in the legal community. This article then turns to $X v$. Latvia, the most significant judgment rendered by the Grand Chamber of the ECtHR in the aftermath of Neulinger. It further analyses, the grounds upon which $X v$. Latvia was decided, in particular, it considers its flaws and virtues. In addition, this article discusses recent judgments of the ECtHR and analyses whether they are in line with the principles contained in $X$ v. Latvia. Finally, it explores the possible way forward for the ECtHR and the domestic courts of the States parties, keeping in mind the general principles laid down by the ECtHR. 
Keywords: European Court of Human Rights, child abduction, best interests of the child, Hague Convention on the Civil Aspects of International Child Abduction, Neulinger and Shuruk v. Switzerland, Xv. Latvia.

\section{O papel controverso do TEDH na interpretação da Convenção da Haia do 25 de outubro de 1980 sobre os Aspectos Civis da Subtração Internacional de Menores: Especial referência aos casos Neulinger e Shuruk c. Suiça e X c. Letônia}

Resumo: o presente artigo explora a recente jurisprudência do Tribunal Europeu de direitos Humanos (TEDH) em matéria de subtração internacional de menores, e faz algumas reflexões sobre seu possível impacto no funcionamento do Convenção sobre os Aspectos Civis do Rapto Internacional de Crianças. Se faz especial referência à sentença Neulinger e Shuruk c. Suiça proferida pela Grande Secção, assim como à "comoção" que produziu na comunidade jurídica. A continuação, examina-se a sentença $X$ c. Letônia a mesma que, depois do assunto Neulinger, tem sido a sentença mais sobressalente emitida pela Grande Secção de dito Tribunal Europeu. Particularmente, se analisam os razoamentos e fundamentos legais de ditas sentenças, destacando tanto suas deficiências quanto suas virtudes. Igualmente, se analisam sentenças recentes do Tribunal Europeu e sua consonância ou divergência com os princípios expostos em $X c$. Letônia. Finalmente, e à luz dos princípios gerais adotados pelo Tribunal Europeu, se considera a direção que deveria tomar dito Tribunal e os tribunais nacionais dos Estados parte.

Palavras-chave: Tribunal Europeu de Direitos Humanos, Subtração de Menores, interesse superior da criança, Convênio da Haia sobre os Aspectos Civis da Subtração Internacional de Menores, Neulinger e Shuruk c. Suiza, X c. Letênia.

\section{Introducción}

El objetivo del presente trabajo es analizar la jurisprudencia del Tribunal Europeo de Derechos Humanos (TEDH) en la interpretación del artículo 8 del Convenio Europeo para la Protección de los Derechos Humanos y 
de las Libertades Fundamentales (CEDH $)^{1}$ y su impacto en la interpretación del Convenio de La Haya de 25 de octubre de 1980 sobre los Aspectos Civiles de la Sustracción Internacional de Menores (CH1980), en particular los principios generales aplicables en dichos casos.

Para ello, se examinarán, en primer lugar, las dos sentencias más relevantes dictadas por la Gran Sala del TEDH en los asuntos Neulinger y Shuruk c. Suiza (en lo subsiguiente, Neulinger) y X c. Letonia. ${ }^{2}$ A continuación, se analizarán sus argumentos en dos vertientes, por una parte con respecto al artículo 13(1)(b) del cH1980 (apartado 3), y por otra, con respecto al artículo 3 del CH1980 y las medidas de protección (apartado 4). Posteriormente, se tratarán las tres sentencias recientes y su consonancia o divergencia con el asunto $X$ c. Letonia (apartado 5). Se terminará con unas conclusiones sobre la percepción crítica de ambas sentencias, la de la interacción del TEDH y el CH1980 en el futuro y si podrían llegar a una feliz simbiosis. En particular, se demostrará que el papel que ha desempeñado el TEDH en la interpretación del CH1980 ha sido controversial. ${ }^{3}$

Recuérdese, primeramente, que la finalidad del CH1980 es la restitución inmediata del menor trasladado o retenido de manera ilícita en cualquier Estado contratante por uno de sus padres o una persona del círculo familiar — como consta en su artículo 1(a)—, salvo que se actualicen algunas de las excepciones indicadas en él (véanse, artículos 12, 13 y 20 del CH1980), y el juez considere en su discreción que el niño no debe ser restituido. Asimismo, el CH1980 tiene como propósito velar para que los derechos de custodia y visita vigentes en uno de los Estados contratantes se respeten en los demás Estados contratantes —artículo 1(b)—.

\footnotetext{
1 Hecho en Roma el 4 de noviembre de 1950 y enmendado por una serie de protocolos. Disponible en: https://www.coe.int/web/human-rights-convention/

El TEDH fue creado de conformidad con el artículo 19 del CEDH a fin de "asegurar el respeto de los compromisos que resultan para las Altas Partes Contratantes de [dicho] Convenio y sus Protocolos".

2 TEDH, Neulinger y Shuruk c. Suiza (Solicitud no. 41615/07), Gran Sala [cita INCADAT: HC/E/CH 1323] y TEDH, X c. Letonia (Solicitud no. 27853/09), Gran Sala [cita INCADAT: HC/E/LV 1234]. Con excepción de los dos casos principal objeto de este estudio, se incluyen las citas de los casos del TEDH en su idioma original (en inglés o francés) a fin de facilitar su búsqueda.

3 El término controversial, admitido por el Diccionario de la Lengua Española, es utilizado aquí en su acepción de controvertido.
} 
Ahora bien, como es sabido, el TEDH desempeña una importante labor interpretativa del respeto a los derechos humanos en Europa aclarando a las jurisdicciones nacionales, en los 47 Estados parte del CEDH, el alcance de sus preceptos en sus decisiones internas. ${ }^{4}$

Si bien el TEDH no interpreta directamente las disposiciones del CH1980, sí es competente para determinar si los tribunales nacionales en sus procedimientos han hecho valer las garantías consagradas en los artículos 6 (derecho a un proceso equitativo) y 8 (asegurar el derecho al respeto a la vida privada y familiar) del $\mathrm{CEDH}$, al interpretar y aplicarlo. ${ }^{5}$ Por lo tanto, el TEDH se ha sumado a la labor de interpretación del CH1980 de manera indirecta y únicamente en lo referente a los derechos humanos.

Por consiguiente, se puede afirmar que este actúa en cierta manera como un tribunal supranacional para los efectos del CH1980. Debe, sin embargo, quedar claro que los tribunales nacionales sí cuentan con un margen de apreciación de los preceptos del CH1980 pero dicho margen está sujeto (eventualmente) a la supervisión del TEDH, quien revisará a la luz de los principios del CEDH, a fin de determinar si se salvaguardaron los derechos humanos de las personas que han intervenido en un caso dado, y de especial relevancia para el presente estudio, si se salvaguardó el interés superior del menor en el caso concreto.

4 Tal como se desprende de su informe anual, el tribunal es víctima de su propio éxito. En 2017, el TEDH desestimó 70356 solicitudes y dictó sentencia solo en 15595 de las 85951 solicitudes decididas. Lo que es un avance significativo, pues implica un aumento aproximadamente del $700 \%$ en el número de sentencias dictadas con respecto al año 2016 (en el cual solo se emitieron 1927 sentencias de un total de 38506 de las solicitudes decididas). Sin embargo, en 2018 hubo una considerable disminución de casos (solo se decidieron 42761 casos). Véase TEDH, Annual Report 2017 and 2018 of the European Court of Human Rights, Council of Europe, p. 163 y p. 167, respectivamente (Chap. 6), https://echr.coe.int/Documents/Annual_report_2017_ENG.pdf y https://echr.coe. int/Documents/Annual_report_2018_ENG.pdf

5 Como se ha indicado anteriormente, las sentencias del TEDH referidas en este estudio se enfocan principalmente en el artículo 8 del CEDH. La profesora Marta Requejo Isidro menciona que en algunas ocasiones el TEDH utiliza indistintamente el artículo $6 \mathrm{u}$ 8 del CEDH en temas de sustracción de menores, sobre todo en cuestiones procedimentales. Véase Marta Requejo Isidro, "El derecho al respeto a la vida privada y familiar y el secuestro internacional de menores. Los estados miembros de la UE ante el TEDH: estado de la cuestión (2016)," Anuario de los cursos de derechos bumanos de Donostia-San Sebastián 16, (2016): 288-289. 
Asimismo, se ha argumentado que en algunas ocasiones el CEDH, y por tanto el TEDH, tienen verdaderos efectos extraterritoriales. Si bien no se han considerado los casos de sustracción de niños como una competencia extraterritorial de los Estados parte, necesariamente el CEDH tendrá una influencia importante cuando la sustracción se lleve a cabo entre un Estado europeo y un tercer Estado, pues el Estado europeo puede ser sancionado por infringirlo, aun si se trata de una restitución de un niño a un tercer Estado (tal y como sucedió en $X c$. Letonia). ${ }^{6}$ Asimismo, se ha considerado que el CEDH cuenta con un carácter de orden público europeo, y por lo tanto, prevalecerá sobre derecho interno u otros tratados aplicables (inclusive de tratados con Estados no miembros de dicho convenio). ${ }^{7}$

En este sentido, conviene destacar que el TEDH se ha pronunciado sobre diversas disposiciones del CH1980, en particular los artículos 3,11, 13(1)(b), 13(2), 16, 20, 21, entre otros, y su relación con el CEDH. ${ }^{8}$ Como se ha indicado anteriormente, de todas las decisiones dictadas interesa destacar, a efectos de este trabajo, los principios generales que se deben aplicar en casos de sustracción de menores, y en particular, poner de relieve la interacción del artículo 8 del CEDH y el CH1980.

Antes de profundizar en el tema, cabe señalar algunos aspectos introductorios con respecto al artículo 8 del CEDH. Como lo indica el profesor William A. Schabas, dicho artículo se divide en cuatro categorías: el derecho al respeto a la vida privada, la vida familiar, el domicilio y la correspondencia. Sin embargo, el título de dicho artículo se centra en "vida privada y familiar", y en efecto, la jurisprudencia en virtud de las primeras dos categorías es muy abundante. ${ }^{9}$ Para efectos del presente estudio, se hará enfasis en la categoría "vida familiar". Cabe señalar que

6 Los efectos extraterritoriales han sido expresamente reconocidos por el tribunal. Véase TEDH, Factsheet - Extra-territorial jurisdiction of States Parties (julio de 2018), https:// www.echr.coe.int/Documents/FS_Extra-territorial_jurisdiction_ENG.pdf. Asimismo, cualquier persona, independientemente de su nacionalidad, puede acudir al TEDH, siempre que la violación que se invoque haya sido cometida por uno de los Estados parte del CEDH y dicha persona esté "bajo su jurisdicción” (véase artículo 1 del CEDH).

7 TEDH, Neulingery Shuruk c. Suiza, \133.

8 La base de datos INCADAT y Paul R. Beaumont, "The Jurisprudence of the European Court of Human Rights and the European Court of Justice on the Hague Convention on International Child Abduction", Recueil des cours 335, (2008): 51-71.

9 Véase William A. Schabas, The European Convention on Human Rights (Oxford: Oxford University Press, 2015), 366. 
dicho artículo establece que no podrá haber injerencia de la autoridad pública en el ejercicio del derecho al respeto a la vida familiar (y de las otras categorías) a menos de que esté prevista por la ley y constituya una medida que sea necesaria en una sociedad democrática. ${ }^{10}$ En efecto, el derecho de los padres e hijos de disfrutar de su compañía mutua (sin injerencia de la autoridad pública) forma parte de la médula del derecho al respeto a la "vida familiar" del artículo 8 del CEDH. ${ }^{11}$

La pregunta radica en si el CH1980, o su puesta en práctica, vulnera los derechos contenidos en dicho numeral, ya que en dichos procedimientos se ordena el retorno del menor al Estado de su residencia habitual (a menos que actualice una excepción) y eso provoca una injerencia del Estado en la relación entre padres e hijos.

La doctrina en un principio se había expresado favorablemente sobre la jurisprudencia del TEDH, haciendo hincapié en que no había cedido a la tentación de ampliar el ámbito del CEDH. ${ }^{12}$ Sin embargo, un vuelco en la postura del TEDH cambió el panorama. La doctrina criticó a la jurisprudencia emitida posteriormente por este, argumentando que había desvirtuado la naturaleza del cH1980 y había convertido a los procedimientos de restitución en verdaderos litigios de custodia. ${ }^{13}$ Ahora bien, en el caso $X$ c. Letonia, el TEDH acertadamente indicó que los procedimientos de restitución no son litigios de custodia. ${ }^{14}$

Sin embargo, en la opinión del profesor Francis G. Jacobs, el estudio de las cuatros partes integrantes del artículo 8 también puede ser realizado de manera colectiva, ya que será más efectivo y amplio que un análisis de cada una de las partes aisladas. Véase, Francis G. Jacobs, The European Convention on Human Rights, (Guildford y London: Oxford University Press, 1975), 125-126.

10 De conformidad con el artículo, dicha medida debe ser "necesaria para la seguridad nacional, la seguridad pública, el bienestar económico del país, la defensa del orden y la prevención de las infracciones penales, la protección de la salud o de la moral, o la protección de los derechos y las libertades de los demás".

11 Schabas, The European Convention, 391.

12 Beaumont, "The Jurisprudence of the European Court of Human Rights...", 51-71.

13 Véase, Lara Walker, "The Impact of the Hague Abduction Convention on the Rights of the Family in the Case-law of the European Court of Human Rights and the UN Human Rights Committee: The Danger of Neulinger", Journal of Private International Law 6, no. 3 (2010): 649-682; Rhona Schuz, The Hague Child Abduction Convention - A Critical Analysis (Oxford: Hart Publishing, 2013), 27-28.

14 TEDH, X c. Letonia, \101 y siguientes. 
Ahora se examinarán ambos asuntos por tratarse de los más sobresalientes para los fines de este estudio. Cabe señalar, no obstante, que anteriormente a Neulinger existieron tres sentencias relativas a los principios generales, que deben aplicar al CH1980 emitidas por la tercera sección (las dos primeras sentencias) y la cuarta sección (la última): Maumousseau y Washington c. Francia, ${ }^{15}$ Deake c. Romania y el Reino Unido ${ }^{16}$ y P.P. c. Polonia. ${ }^{17}$ Sin embargo, como se ha indicado anteriormente, la Gran Sala del TEDH ${ }^{18}$ se ha pronunciado en dos ocasiones sobre la interpretación del CH1980 y su interacción con el CEDH: ${ }^{19}$ Neulingery Shuruk c. Suiza y X c. Letonia. La última sentencia aclara (sin expresamente revocar) el alcance de Neulinger.

\section{E1 caso Neulinger}

La Gran Sala del TEDH se pronunció por vez primera sobre el CH1980 en la sentencia Neulinger del año 2010, que creó conmoción en la comunidad jurídica, como se explicará más adelante. A manera de antecedente, cabe señalar que dicho caso fue primeramente admitido por la primera sección del TEDH. Esta sección decidió por mayoría de 4 votos contra 3, que no se había infringido el derecho al respeto a la vida familiar de la madre y el niño de conformidad con el artículo 8 del CEDH. ${ }^{20}$ En este apartado, se analizará exclusivamente la sentencia Neulinger emitida por la Gran Sala, toda vez que la sentencia de la primera sección fue revocada y pese a su interés jurídico, carece de relevancia en la aplicación del CH1980.

15 TEDH, Maumousseau and Washington v. France (Application no. 39388/05) [cita INCADAT: $\mathrm{HC} / \mathrm{E} / \mathrm{FR}$ 942].

16 TEDH, Deak v. Romania and the United Kingdom (Application no. 19055/05) [cita INCADAT: HC/E/UKe 974].

17 TEDH, P.P. v. Poland (Application no. 8677/03) [cita INCADAT: HC/E/PL 941].

18 Las atribuciones de la Gran Sala se establecen en el artículo 31 del CEDH, una de ellas es la remisión del asunto a la Gran Sala (equiparable a un tribunal de apelación), la cual debe ocurrir dentro de los 3 meses a partir de la sentencia de una Sala (véase, asimismo el artículo 43 del CEDH).

19 Cabe señalar que la Gran Sala solamente conoce de un porcentaje muy reducido de casos, de todas las solicitudes de "apelación" solamente procede el $5 \%$. Por ejemplo, recientemente los fallos de la Gran Sala fueron de 2323 y los de la sala son de 38840. Véase asimismo http://www.echr.coe.int/Documents/Note_GC_ENG.pdf

20 TEDH, Neulinger and Shuruk v. Switzerland (Application no. 41615/07) [cita INCADAT: $\mathrm{HC} / \mathrm{E} / \mathrm{CH}$ 1001]. 
Los hechos de este caso son los siguientes: un matrimonio de una nacional de Suiza (y Bélgica) y un nacional de Israel, ambos judíos, tuvieron un niño nacido en Israel; el niño contaba con la doble nacionalidad suiza e israelí. El conflicto en el matrimonio se originó porque aparentemente el padre ingresó en una secta judía ultra ortodoxa (organización Lubavitch), y la madre no estaba de acuerdo. Debido a lo conflictivo del matrimonio, los servicios sociales israelís tuvieron que intervenir solicitándoles vivir por separado. Posteriormente, los padres se divorciaron, y como resultado, se otorgó la custodia a la madre y el derecho de visita al padre. Sin embargo, existía una orden que prohibía trasladar al niño fuera de Israel. ${ }^{21} \mathrm{~A}$ pesar de ello, la madre sustrajo al menor y lo trasladó a Suiza, país originario de la madre. ${ }^{22}$ Después de acudir a diferentes instancias en Suiza, la Corte Federal suiza ordenó el regreso del menor a Israel, concluyendo que el menor no estaba expuesto a un grave riesgo; es decir, no existía un grave riesgo de que la restitución expusiera al menor a un peligro grave físico o psíquico, o que de cualquier otra manera pusiera al menor en una situación intolerable —artículo 13(1)(b) del cH1980-.

Posteriormente, la madre acudió ante el TEDH. Debido a que la sentencia de la primera sección del TEDH fue desfavorable, se solicitó la remisión del asunto ante la Gran Sala, la cual fue aceptada. Esta resolvió, 16 votos a favor y uno en contra, que se infringiría el derecho al respeto a la vida familiar de la madre y el niño, de conformidad con el artículo 8 del CEDH si se ejecutara la decisión que ordenaba el retorno del niño. La sentencia Neulinger, emitida por la Gran Sala, parecía establecer parámetros para los tribunales de los Estados parte en los casos de sustracción internacional de menores. En concreto, el tribunal sostuvo que en los casos de restitución de menores (medida impugnada en el caso que se presenta) los procesos deben de ser justos y permitir que todas las personas

21 Si bien la madre solicitó dicha orden al inicio del procedimiento, posteriormente solicitó su revocación, que le fue denegada, debido al riesgo de que la madre no regresase con el menor. Las órdenes que prohíben el traslado del menor del país donde reside constituyen derechos de custodia para los efectos del CH1980, como ha sido ampliamente reconocido en la jurisprudencia internacional. A manera de ejemplo, véase el caso resuelto en la Suprema Corte de Estados Unidos de América: Abbott v. Abbott, 130 S. Ct. 1983 (2010) [cita INCADAT: HC/E/USf 1029].

22 Las peripecias de la madre fueron plasmadas en su libro autobiográfico: Isabelle Neulinger, Jamais vous n'aurez, mon fils (Paris: Jourdan PixL, 2015), 153-180. 
involucradas puedan hacer valer plenamente sus derechos, ${ }^{23} \mathrm{y}$ añadió que (véase párrafo 139 de Neulinger):

[...] [t]o that end the Court must ascertain whether the domestic courts conducted an in-depth examination of the entire family situation and of a whole series of factors, in particular of a factual, emotional, psychological, material and medical nature, and made a balanced and reasonable assessment of the respective interests of each person, with a constant concern for determining what the best solution would be for the abducted child in the context of an application for his return to his country of origin (see Maumousseau and Washington [...])"24 (El énfasis propio pues se quiere destacar justamente el carácter controversial de este párrafo).

Cabe señalar que Neulinger —en su fundamentación— parte de la sentencia Maumousseau, pero, al mismo tiempo, va más allá, ya que amplía su ámbito de aplicación, lo que produce una revocación de sus principios. ${ }^{25}$ En efecto, Maumousseau interpreta de manera restrictiva el artículo 13(1)(b) del CH1980 con base en que los Estados contratantes facilitarán el regreso del menor, y el país de la residencia habitual resolverá el litigio sobre la custodia; asimismo, reconoce que el tribunal nacional hizo un examen exhaustivo del conjunto de la situación familiar y otros elementos, y señaló que no se actualizaba la excepción del artículo 13 del CH1980. Sin embargo, en ningún momento, Maumousseau establece un criterio obligatorio relativo a que debe realizarse un examen exhaustivo de la situación del niño.

Posterior a Neulinger, fueron dictadas dos sentencias y una decisión que confirmaban ese criterio para los casos sobre sustracción, por la

\footnotetext{
23 Este criterio fue tomado de Maumousseau and Washington v. France.

24 TEDH, Neulingery Shuruk, c. Suiza \$139. Traducción de la autora: A este fin, el Tribunal deberá verificar si las jurisdicciones nacionales han efectuado un examen exhaustivo de la totalidad de la situación familiar y de toda una serie de elementos, de orden fáctico, afectivo, psicológico, material y médico, y si han apreciado de manera equilibrada y razonada los intereses de cada una de las personas, con la preocupación constante de determinar cuál sería la mejor solución para el niño sustraído en el contexto de una solicitud de restitución a su país de origen (véase Maumousseau and Washington [...]).

25 Como atinadamente lo indica el voto disidente del juez Zupančič, esta sentencia a pesar de que invoca Maumousseau, la revoca en sus conclusiones.
} 
tercera, segunda y primera secciones, respectivamente (orden cronológico):

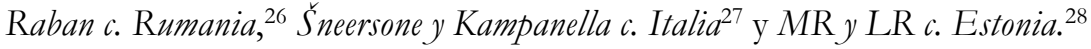

Dichos pronunciamientos han generado mucha controversia y preocupación en el seno de la Conferencia de La Haya de Derecho Internacional Privado ${ }^{29}$ (en lo subsiguiente, Conferencia de La Haya), así como en otros foros. ${ }^{30} \mathrm{El}$ anterior Secretario General de la Conferencia de La Haya, Hans van Loon, se dirigió al Committee of Legal Advisers on Public International Law $^{31}$ del Consejo de Europa el 17 de marzo de 2011 en Estrasburgo para subrayar esta preocupación. ${ }^{32}$ En particular,

26 TEDH, Raban v. Romania (Application no. 25437/08) [cita INCADAT: HC/E/RO 1330].

27 TEDH, Šneersone and Kampanella v. Italy (Application no. 14737/09) [cita INCADAT: HC/E/ LV 1152].

28 TEDH, MR and LR v. Estonia (Application no. 13420/12) (declarado inadmisible) [cita INCADAT: HC/E/EE 1177].

29 La Conferencia de La Haya es una organización intergubernamental en cuyo seno se negoció el CH1980, la cual está encargada de dar seguimiento y monitorear activamente el funcionamiento de los Convenios de La Haya.

30 La autora participó, en su calidad de miembro de la Oficina Permanente de la Conferencia de La Haya de Derecho Internacional Privado, en las reuniones de la Comisión Especial sobre el Funcionamiento de los Convenios de La Haya de 1980 sobre Sustracción de Menores y 1996 sobre Protección de Niños, y pudo ser testigo de la preocupación que se generó en los Estados contratantes por la jurisprudencia del TEDH.

Véase, Conclusiones y Recomendaciones de la Comisión Especial sobre el funcionamiento práctico del Convenio sobre Sustracción de Menores de 2011 no. 48, la cual transcribimos a continuación:

"La Comisión Especial destaca las serias preocupaciones que se han expresado con relación a los términos empleados por el tribunal en sus sentencias recientes dictadas en el marco de los casos Neulinger and Shuruk v. Switzerland (Gran Sala, no. 41615/07, 6 de julio de 2010) y Raban v. Romania (no. 25437/08, 26 de octubre de 2010), en tanto podrían interpretarse como 'requiriendo que los tribunales nacionales abandonen el enfoque rápido y sumario que el Convenio de La Haya contempla y se aparten de una interpretación restrictiva de las excepciones del artículo 13 hacia una evaluación completa e independiente de las cuestiones de fondo generales de la situación. (conf. Presidente del Tribunal Europeo de Derechos Humanos, extrajudicialmente' (Info. Doc. no. 5)".

31 Comité de consejeros jurídicos de derecho internacional público.

32 Véase Hans van Loon, Interaction Between Recent Case-law of the European Court of Human Rights and the Hague Convenion of 25 October 1980 on the Civil Aspects of International Child Abduction, 17 de marzo de 2011, http://www.hcch.net/upload/coe2011.pdf

Si bien en este comunicado el Secretario General menciona la necesidad de revisar Raban v. Romania, debido a la incertidumbre que generó por haber extendido el ámbito de aplicación de Neulinger, el correspondiente colegio del TEDH rechazó la remisión ante la Gran Sala 
un discurso extrajudicial del presidente del TEDH causó mucho revuelo, pues intentó aclarar y restringir los efectos de Neulinger. ${ }^{33}$ Dicho discurso pudiera ser considerado como una respuesta al discurso del Secretario General mencionado.

Asimismo, el criterio de Neulinger fue expresamente rechazado por la Suprema Corte de Reino Unido al considerarlo inadecuado. ${ }^{34}$ No obstante, dicha Suprema Corte dictó una resolución acorde a los principios del TEDH, ya que consideró que el tribunal de apelaciones no consideró debidamente los alegatos de la madre en relación con el artículo 13(1) (b) del cH1980.

En nuestra opinión, la sentencia Neulinger adolece de algunas contradicciones. Primera, requiere a los tribunales hacer un estudio detallado y exhaustivo de las circunstancias, y al mismo tiempo, que estos de forma expedita dentro de las 6 semanas, término no obligatorio según el CH1980 aunque sí recomendado, tomen una decisión. Esta exigencia deja a los tribunales nacionales ante una compleja posición al tener que aunar exhaustividad en el análisis y celeridad en la toma de decisiones. ${ }^{35}$

(artículo 43 del CEDH). TEDH, Press release issued by the Registrar of the Court, no. 377 of 28 April 2011.

33 Conclusiones y Recomendaciones de la Comisión Especial de 2011 no. 49:

"La Comisión Especial destaca una reciente declaración extrajudicial realizada por el Presidente del Tribunal Europeo de Derechos Humanos (ver arriba), en la cual afirma que la decisión emitida en el marco del caso Neulinger and Shuruk v. Switzerland no indica un cambio de dirección para el tribunal con competencia en materia de sustracción de niños y que la lógica del Convenio de La Haya consiste en que todo niño que haya sido sustraído debería ser restituido al Estado de su residencia habitual y es solamente allí donde su situación debería analizarse en su totalidad".

34 Re S. (A Child) (Abduction: Rights of Custody) [2012] UkSC 10, [2012] 2 A.C. 257 [cita INCADAT: HC/E/UKe 1147] (Reino Unido). La decisión indica "[w]ith the utmost respect to our colleagues in Strasbourg, we reiterate our conviction, as Reunite requests us to do, that neither the Hague Convention nor, surely, article 8 of the European Convention requires the court which determines an application under the former to conduct an in-depth examination of the sort described. Indeed it would be entirely inappropriate". Traducción de la autora: Con el mayor respeto a nuestros colegas en Estrasburgo, reiteramos nuestra convicción, como lo solicita Reunite, que ni el Convenio de La Haya ni seguramente el artículo 8 del CEDH requiere al tribunal que conoce de una solicitud en virtud del Convenio de La Haya a realizar un examen exhaustivo del tipo descrito. En efecto, esto sería totalmente inadecuado.

35 Véase por ejemplo, TEDH, Karrer v. Romania (Application no. 16965/10) [cita INCADAT: $\mathrm{HC} / \mathrm{E} / \mathrm{RO} 1149]$ \54-55. 
Segunda, parece no tomar en cuenta que las pruebas se encuentran en el Estado de la residencia habitual del niño y por tanto, es fácticamente imposible hacer un examen exhaustivo de la situación del niño en tiempo tan breve. Tercera, aplica criterios establecidos por ese tribunal en la expulsión de extranjeros en situación migratoria irregular, ${ }^{36}$ a pesar del principio ampliamente reconocido según el cual la restitución del menor no equivale a una deportación o extradición. Por consiguiente, sugerimos a los tribunales abandonar dichos criterios, ya que son infundados. Cuarta, indica que el CH1980 es un tratado eminentemente procesal ${ }^{37}$ lo que no es acertado, ya que este hace efectivos los derechos humanos de los niños, consagrados en los artículos 10(2) y 11 de la Convención de Naciones Unidas sobre los Derechos del Niño. ${ }^{38}$

\section{E1 caso $X$ c. Letonia}

Solamente tres años tras haberse pronunciado en Neulinger, la Gran Sala del TEDH resolvió nuevamente un caso de sustracción de menores en el asunto $X$ c. Letonia, el cual pone de relieve cuáles son los criterios del TEDH en este tema, y por ello, su indiscutible importancia.

Conviene señalar que dicha sentencia no revoca Neulinger sino que aclara sus alcances. Lo anterior, debido a que, al parecer, la Gran Sala no es muy afecta a revocar sus propias sentencias, por lo menos no expresamente. Considérese que la presión ejercida por los diferentes gobiernos, tribunales y organizaciones internacionales (tales como la Conferencia de La Haya) fue vital para el cambio de parecer del TEDH.

Se trata de una interpretación bienvenida y ansiada por los tribunales europeos y diferentes círculos doctrinales. ${ }^{39}$ Sin embargo, cabe señalar que existe, en algunos foros, incertidumbre sobre el verdadero alcance de

En dicho caso, se concluyó que el tribunal de apelación en Rumanía se excedió en el tiempo para resolver el caso, dado que el procedimiento duró 11 meses y no se justificó adecuadamente la causa de la dilación.

36 TEDH, Neulinger y Shuruk. c. Suiza, \$146.

37 Ibíd., \ 145.

38 Véase Sharon Detrick, A Commentary on the United Nations Convention on the Rights of the Child (The Hague: Kluwer Law International, 1999), 183-191, 203-212.

39 Alexandre Boiché, "Enlèvement International d'enfants: la Cour européenne des droits de l'homme revient sur sa jurisprudence Neulinger", AJ Famille, (2014): 58. 
la sentencia $X c$. Letonia. $^{40}$ De ahí que durante la reunión de octubre de 2017 de la Comisión Especial sobre el funcionamiento práctico del CH1980, celebrada en La Haya, Países Bajos, se adoptara una conclusión neutral, sin celebrar ni repudiar el fallo: ${ }^{41}$

De acuerdo a las Conclusiones y Recomendaciones $\mathrm{N}^{\circ} 48$ y 49 de la Sexta Reunión de la Comisión Especial de 2011 (primera parte), la Comisión Especial señala los avances realizados con posterioridad a la reunión, en el asunto X c. Letonia, en particular el examen del Tribunal que figura en la sección "Principios generales" (párrs. 92-108), en el que la Gran Sala del Tribunal Europeo de Derechos Humanos afirmó, entre otras cosas, que "cuando se trate de una demanda de retorno efectuada en aplicación del Convenio de La Haya, situación distinta a la de un procedimiento sobre el derecho de custodia, se deberá apreciar el interés superior del niño teniendo presentes [a la luz de] las excepciones previstas en dicho convenio [referencias a los arts. 12, 13 y 20 del Convenio de La Haya sobre Sustracción de Niños]" (Gran Sala, N²7853/09, 26 de noviembre de 2013, párr. 101; véase también el párr. 107, en el que la Gran Sala destacó que estas excepciones "se interpretarán de manera estricta").

Como se verá a lo largo de este artículo, y a pesar de este aparente velo de duda sobre su interpretación, la autora considera que esta sentencia es favorable y ha aclarado temas inciertos en relación con la interacción de ambos tratados. Sin embargo, se coincide con que en esta materia no existe una claridad perfecta, y dicho criterio, admite amplia flexibilidad a los tribunales.

40 Véanse por ejemplo: Requejo Isidro, "El derecho al respeto a la vida privada y familiar...", 312-313; Peter McEleavy, "The European Court of Human Rights and the Hague Child Abduction Convention: Prioritising Return or Reflection?," Netherlands International Law Review 62, no. 3 (2015), 392-403, https://doi.org/10.1007/s40802-0150040-z.

Algunos autores han manifestado su preocupación y no han estado de acuerdo con el resultado, entre ellos: Paul Beaumont, Katarina Trimmings, Lara Walker y Jayne Holliday, "Child Abduction: Recent jurisprudence of the European Court of Human Rights," International and Comparative Law Quarterly 64, no.1 (2015): 48, https://doi.org/10.1017/ S0020589314000566

41 Conclusión y Recomendación no. 17 de la Comisión Especial sobre el funcionamiento práctico de los Convenios de La Haya de 1980 y 1996 (10-17 de octubre de 2017). 
Los hechos del caso son los siguientes: El menor nació en Australia de padres de nacionalidad letona (la madre, la cual adquirió la nacionalidad australiana en 2007 y contaba, por tanto, con la doble nacionalidad) y australiana (el padre). La madre letona se mudó con el padre australiano cuando ya se encontraba en los últimos meses del embarazo. A pesar de la mala relación entre ambos padres, la madre siguió viviendo en el apartamento del padre en Australia en calidad de arrendataria. Posteriormente, la madre sustrajo al menor de Australia en julio de 2008, sin el consentimiento del padre, y por ello, el padre interpuso una solicitud de restitución en septiembre de ese año. Los padres nunca estuvieron casados ni eran pareja de hecho. Un tribunal australiano otorgó responsabilidad parental al padre en un procedimiento posterior a la sustracción, sin aparentemente otorgarle garantía de audiencia y defensa a la madre (véase infra para información más detallada). Un tribunal de Riga ordenó el retorno del menor, pero la madre apeló alegando la excepción del artículo 13(1)(b) del ch1980 (véase infra para información más detallada). Posteriormente, el tribunal de alzada desestimó la apelación como infundada. El padre viajó a Letonia e hizo justicia por su propia mano al despojar a la madre del menor en un lugar público y llevarlo consigo a Australia (véase infra para más información sobre las consecuencias de dicho acto).

A primera vista, pareciera que la sentencia $X c$. Letonia fue reñida en cuanto a fijar parámetros para la aplicación del cH1980. Pero no fue así, ya que la controversia principal entre los jueces únicamente versó sobre si se debía condenar a Letonia. La mayoría concluyó que la solicitante sufrió una interferencia desproporcionada en su derecho a la vida familiar, ya que la decisión emitida en virtud de derecho nacional no satisfizo los requisitos inherentes del artículo 8 del CEDH, en base a que el tribunal regional de Riga no consideró debidamente los alegatos de la solicitante en virtud del artículo 13(1)(b) del CH1980. ${ }^{42}$

42 Como dato curioso señalamos que el juez de Letonia fue parte de la mayoría y por tanto, votó a favor de la condena de Letonia. Los jueces de la mayoría eran de Bulgaria, Estonia, Grecia, Letonia, Liechtenstein, Lituania, Luxemburgo, Montenegro y Portugal. Los jueces disidentes: Alemania, Azerbaiyán, Chipre, Croacia, Eslovaquia, Finlandia, Italia y Reino Unido. Obsérvese que las grandes potencias como Alemania, Italia y Reino Unido votaron en contra de la mayoría dado que hubieran preferido que Letonia no fuera condenado, para así evitar fijar un criterio de difícil cumplimiento para los tribunales. Naturalmente, varios de los jueces ya concluyeron sus términos y fueron reemplazados por nuevos jueces de su respectivo país. No obstante, dicha sentencia no deja de ser 
De manera unánime, los jueces del TEDH estuvieron de acuerdo en realizar una interpretación armónica del CEDH y del CH1980. De una manera clara y acertada, los jueces expusieron que un análisis de las disposiciones de los tratados internacionales no debería resultar en un conflicto o contradicción entre los diferentes tratados, siempre que el TEDH pueda realizar su objetivo de garantizar la observancia de los compromisos de los Estados contratantes. Posteriormente, señala la sentencia que debe existir un equilibrio entre los diferentes intereses del menor, los padres y el orden público. Añade que existe un consenso internacional sobre que el interés superior del menor debe ser primordial. Asimismo, indica que el CH1980 sigue la misma filosofía de restablecer el statu quo y menciona las excepciones. Aclara, además, que los procedimientos sobre sustracción son diferentes a los procedimientos de custodia. ${ }^{43}$

En la sentencia $X c$. Letonia, los votos del TEDH se dividieron 16 contra 1 en relación con el criterio adoptado por Neulinger. Casi por unanimidad, los jueces (excepto por el juez Pinto de Albuquerque de Portugal) estuvieron de acuerdo en que el artículo 8 del CEDH no obliga a los jueces nacionales a hacer un examen exhaustivo de la totalidad de la situación familiar y de toda una serie de elementos de orden fáctico, afectivo, psicológico, material y médico, si han apreciado de manera equilibrada y razonada los intereses de cada una de las personas, con la preocupación constante de determinar cuál sería la mejor solución para el niño sustraído en el contexto de una solicitud de restitución a su país de origen (véase, párrafo 105 de Xc. Letonia). Por lo que, en efecto, cambia el criterio establecido en Neulinger (en su párrafo 139), dicho criterio hubiera desprovisto al CH1980 de todo significado, al convertirlo en un proceso de custodia. ${ }^{44}$

controversial y de gran alcance, por ello es posible que jueces del TEDH, sin importar cuándo fueron designados o si participaron o no en las deliberaciones, cuenten con su propia opinión personal sobre el caso. Conversación con el juez español del Tribunal Europeo, Luis López Guerra, el 25 de septiembre de 2014 en Estrasburgo, Francia, en el marco de la Jornada "Tribunal Europeo Derechos Fundamentales" de la Facultad de Derecho de la UNED.

43 TEDH, X c. Letonia, \92-102.

44 Este cambio parece lógico pues las intervenciones tanto de gobiernos (Finlandia y la República Checa), así como la organización no gubernamental Reunite manifestaron su preocupación con la actual tendencia del TEDH a prácticamente desvirtuar el objetivo del CH1980. Asimismo, en otros foros, incluyendo el de la Conferencia de La Haya se hizo 
Sin embargo, al parecer, el tribunal buscó un término medio, y por ello, exigió que dos condiciones se cumpliesen para una interpretación armónica del CEDH y el CH1980 (véase, párrafo 106 de X c. Letonia). Por una parte, los elementos susceptibles de constituir una excepción para el regreso inmediato del menor con respecto a los artículos 12,13 y 20 del CH1980, particularmente cuando los invoque una de las partes, deben ser realmente tomados en cuenta por el tribunal requerido; asimismo, el tribunal debe motivar su decisión sobre este punto a fin de permitir al TEDH verificar que estos elementos fueron objeto de un examen efectivo. Por otra parte, dichos elementos deben ser evaluados a la luz del artículo 8 del CEDH. Luego de ello, el TEDH hace una acotación de no poca importancia: "véase Neulinger". No es clara la intención del Tribunal Europeo al añadir dicha acotación, dado que Xc. Letonia, de cierta manera, "revoca" implícitamente el criterio de Neulinger sobre el examen exhaustivo, al cambiar la postura del TEDH por mayoría de votos. No obstante, dicha acotación pareciera referirse únicamente al párrafo 133 de Neulinger sobre la naturaleza de orden público europeo de dicho instrumento, con respecto a si los tribunales nacionales han actuado conforme a las garantías consagradas en el CEDH. El futuro indicará cómo dicho criterio se aplicará en los tribunales nacionales de los Estados parte del CEDH.

En lo que respecta a la condena a Letonia por haber infringido el artículo 8 del CEDH conviene hacer algunas precisiones. El TEDH se encuentra dividido y el voto fue bastante controvertido en relación con el argumento relativo a que el tribunal regional de Riga no consideró debidamente los alegatos de la solicitante en virtud del artículo 13(1) (b) del CH1980. La diferencia entre los jueces radica en el control que debe ejercer el TEDH sobre los tribunales nacionales, y en particular, en el actuar de dichos tribunales cuando se invoquen las excepciones en virtud del CH1980. La mayoría de los votos (9 contra 8) le confiere mayor responsabilidad a los tribunales en materia probatoria y al evaluar las excepciones, reconociendo que estos pueden recabar pruebas de oficio cuando así se contemple en el derecho interno; en cambio, el criterio de la minoría subraya que son las partes las que tienen la carga de la prueba y no corresponde al tribunal ir más allá de lo establecido y probado por ellas.

hincapié en la necesidad de revertir esos criterios. En otras palabras, el TEDH se encontraba prácticamente sitiado. 
Se debe reconocer que el criterio de la mayoría de los miembros del TEDH en lo que respecta a la actuación de los tribunales en materia probatoria — reconociendo la posibilidad de actuar de oficio—, es mucho más oneroso y difícil de implementar. Surge la pregunta de si sería adecuado plantear esta disyuntiva en casos de sustracción de menores. Desde una perspectiva estricta del CH1980, la respuesta debería ser negativa. Dicha interpretación posiblemente llevaría a la interposición de más recursos y argucias jurídicas por parte de las partes, lo que alargaría los litigios y posiblemente generaría incertidumbre jurídica.

Mas, en opinión de la autora, el cH1980 debe conciliarse con los tratados existentes de derechos humanos y la evolución de los derechos de los niños, y adaptarse a la evolución de la sociedad en la cual en la gran mayoría de casos, son las madres las que sustraen al menor; ${ }^{45}$ en algunas ocasiones, las madres se encuentran huyendo de violencia doméstica. ${ }^{46}$ Es decir, ahora son las personas responsables del cuidado principal del menor las que sustraen a los niños.

Por lo anterior, en vista de la vulnerabilidad de las personas involucradas, los tribunales deben cerciorarse, por los medios probatorios presentados por las partes o recabados de oficio, de que el menor no se encuentra en grave riesgo, particularmente cuando fuera invocado por las partes. En caso de que se encontrara, el tribunal tendrá la discreción de determinar qué medidas protectoras son suficientes para proteger al menor al regresarlo a su país de residencia habitual.

Parece una prioridad evitar resultados injustos como lo fue el caso que dio lugar a $X$ c. Letonia. En particular, al regreso de la madre, el tribunal australiano emitió una decisión en la que otorgaba al padre responsabilidad parental de manera exclusiva y permitía a la madre visitar al menor bajo la supervisión de una trabajadora social. Asimismo prohibió, entre otras cosas, a la madre hablar al menor en letón.

45 Nigel Lowe, Victoria Stephens, Part I - A statistical analysis of applications made in 2015 under the Hague Convention of 25 October 1980 on the Civil Aspects of International Child Abduction - Global report - provisional edition, pending the completion of the French version, Conferencia de La Haya de Derecho Internacional Privado, Documento Preliminar no. 11 de febrero de 2018 - revisado, 7-8, https://assets.hcch. net/docs/d0b285f1-5f59-41a6-ad83-8b5cf7a784ce.pdf

46 Taryn Lindhorst y Jeffrey L. Edleson, Battered Women, their Children, and International Law - The Unintended Consequences of the Hague Child Abduction Convention (Boston: Northeastern University Press, 2012): 104-107. 
El TEDH asumió el riesgo y lo felicitamos, al fin y al cabo, el criterio sobre la admisión y ofrecimiento de pruebas establecido por la sentencia $X$ c. Letonia se aplicará en casos restringidos (en particular, cuando se invoquen excepciones en virtud del artículo 13). A pesar de este logro, aún existe el riesgo de que se compliquen excesivamente los casos de sustracción de menores, ya que no existen lineamientos para los tribunales nacionales. En efecto, el TEDH deja abierta la puerta a las interpretaciones que de este criterio hagan los tribunales nacionales, y probablemente incrementará el volumen de casos que se presenten ante este. Sin embargo, aproximadamente seis años después de la emisión del fallo no se observa un incremento que sea digno de mencionarse.

Algunos reputados autores se han manifestado en contra de la condena a Letonia y han advertido que el TEDH debe renunciar a actuar como la última instancia de apelación, sustituyéndose a las opiniones de los tribunales nacionales y retrasando los procedimientos en casos donde es imperativo que estos se resuelvan con celeridad. Asimismo, dichos autores concluyen que se puede estar causando más daño a los niños, ya que no puede restablecerse el statu quo. ${ }^{47}$

La autora no coincide con esta opinión. ${ }^{48}$ Se debe aceptar que la celeridad de los procesos ya ha dejado de ser una excusa cuando se valora

47 Paul Beaumont et al., "Post Neulinger Case Law of the European Court of Human Rights on the Hague Child Abduction Convention," en A Commitment to Private International Law, Essays in honour of Hans van Loon, (Reino Unido: Intersentia, 2013), 30.

Esta crítica, sin embargo, fue realizada antes de que se emitiera la sentencia final por la Gran Sala, y los autores criticaron especialmente la sentencia de una sala de la sección tercera del TEDH. Véase asimismo nota a pie de página 40 .

48 Se suman a nuestra crítica profesores de derechos humanos, como el profesor asociado, Antoine Buyse, de la Universidad de Utrecht en los Países Bajos que mantiene un ECHR blog, en el cual indica "We therefore believe that the ECHR got it "right" in this case [X v. Letonia] by stressing the assessment in relation to an individual child rather than paying "lip service" to the Hague Convention. This Convention may be viewed to provide a "greater good", yet it cannot ignore the reality of the individual child in view of the fact that at times primary carers can also be the main abductors." Traducción elaborada por la autora: Consideramos que el TEDH fue acertado en este caso [X c. Letonia] al subrayar que se debe evaluar con respecto al niño en específico en lugar de favorecer al CH1980 de dientes para afuera. Este CH1980 puede ser percibido como que otorga "un bien mayor", pero al mismo tiempo no puede ignorar la realidad del niño en específico en vista de que en algunas ocasiones los que tienen el cuidado principal del menor también pueden ser los sustractores. Antoine Buyse, http:/ / echrblog.blogspot.nl/2013/12/x-v-latvia-childabduction-grand.html. 
la protección de los derechos humanos y que los derechos humanos se encuentran más presentes que nunca. Sin embargo, la demora debe ser razonable. ${ }^{49}$ El TEDH debe sin duda agilizar sus procesos porque son ahora demasiado prolongados. Por causa de dichas dilaciones en los procedimientos, es muy poco probable que el TEDH ordene un retorno del niño por el tiempo que ha transcurrido desde la sustracción, pero podrá en cambio concluir que existirá una violación al artículo 8 si se ejecuta una orden de retorno dictada por las autoridades nacionales, como en el caso de Neulinger, lo que tendrá como consecuencia la suspensión indefinida de dicha ejecución.

Por lo anterior, y para concluir este apartado, se señala que se coincide con que Letonia infringió el artículo 8 del CEDH. Dicha violación se basa en tres razonamientos (que van, en efecto, más allá del criterio de la mayoría): el tribunal letón no consideró efectivamente la excepción de grave riesgo en el artículo 13(1)(b) (apartado 3); tampoco tomó las medidas de protección adecuadas para la restitución del menor, y determinó de manera errónea que existió un traslado ilícito y que los derechos de custodia habían sido efectivamente ejercidos basándose en una "orden de persecución” de un tribunal australiano (ambos en el apartado 4).

\section{Análisis del caso $X$ c. Letonia en relación con el artículo 13(1)(b) del CH1980}

De conformidad con el artículo 13(1)(b) del ch1980, la persona, institución u otro organismo que se opone a su restitución deberá demostrar que existe "un grave riesgo de que la restitución del menor lo exponga a un peligro grave físico o psíquico o que de cualquier otra manera ponga al menor en una situación intolerable". Se debe aclarar que la excepción de

Véase también Brett Crumley, "X v Latvia: Creative Harmony, Fortunate Result" Oxford Human Rights Hub, http://ohrh.law.ox.ac.uk/?p=3490

Pareciera ser que esta divergencia de opiniones se manifiesta entre profesores de derecho internacional privado y profesores de derechos humanos.

49 Véase por ejemplo, la tesis mexicana Tesis III.2o.C.71 C(10a), Gaceta del Semanario Judicial de la Federación, Décima Época, Libro 40, marzo de 2017, tomo IV, p. 2639 (Registro no. 2013812) "Convención sobre los Aspectos Civiles de la Sustracción Internacional de Menores. atento al interés superior de éstos, el plazo de seis semanas que la autoridad judicial o administrativa competente tiene para resolver los procedimientos para la restitución de aquéllos, al poder excederse de ese periodo razonable y proporcional con la causa que lo originó, no está por encima del derecho de audiencia y defensa de las partes". 
este artículo, así como las demás excepciones contempladas en el cH1980, contemplan el interés superior del menor en el caso concreto, y deben ser interpretadas de manera restrictiva. Sin embargo, deben ser debidamente consideradas, y en su caso, verificar si existen suficientes medidas de protección si existiera riesgo y se ordenara la restitución del menor.

Ahora bien, se explicarán a continuación los hechos del asunto $X c$. Letonia que son relevantes al análisis de la excepción del artículo 13(1)(b) que se propone en este trabajo. En dicho caso, la madre había presentado argumentos en primera instancia que el padre tenía antecedentes penales y había maltratado a la familia. Posteriormente en apelación, presentó un certificado emitido por un psicólogo en relación al riesgo psicológico del menor a ser separado de la madre. La mayoría del TEDH indicó que los tribunales letones debieron tratar de verificar esa información a fin de determinar si existía o no un grave riesgo. ${ }^{50}$ Por otro lado, la minoría consideró que el certificado únicamente trataba sobre el inmediato riesgo psicológico de la separación, no de manera concreta el tema sobre el regreso del menor, por lo que consideró que debida cuenta del contenido, el tribunal no tenía que haber ido más allá; además que los alegatos en contra del padre no fueron demostrados y que la madre no tenía ningún impedimento en regresar a Australia, se ha debido confiar en el sistema australiano.

Asimismo, dicho razonamiento del TEDH pareciera recordar un mecanismo similar a la "suplencia de la queja", contemplado en algunos ordenamientos jurídicos, ya que consideró que el tribunal pudo haber actuado de oficio para hacer un análisis efectivo de los alegatos en base al artículo 13 del CH1980, solicitando por ejemplo, el cross-examination (repreguntas a un testigo no ofrecido por la parte) del informe psicológico u ordenando un segundo informe de un experto sobre el tema. Cabe subrayar que el derecho de Letonia admite que el tribunal pueda actuar de oficio para obtener pruebas, lo que no aconteció en el presente caso. ${ }^{51}$

Ahora bien, de conformidad con el artículo 13 del cH1980, la carga de la prueba recae en la persona, institución u otro organismo que se opone a su restitución. Adicionalmente, en algunos países el juez natural puede recabar pruebas de oficio. Lo anterior tiene sentido, ya que el juez debe velar por el interés superior del menor en el caso concreto y protegerlo.

\footnotetext{
50 TEDH, Xc. Letonia, $\int 116$.

51 TEDH, X c. Letonia, $\int 45$.
} 
Además, algunos Estados, como los latinoamericanos están vinculados por tratados de derechos humanos al respecto; por ende, se ha estimado en México, en tesis de tribunales colegiados de circuito, que el juez está facultado para recabar oficiosamente pruebas en el procedimiento de restitución cuando existen indicios de un grave riesgo. ${ }^{52}$

En este sentido, es falaz afirmar que únicamente las pruebas presentadas por las partes deben ser estimadas para los procedimientos de restitución, cuando haya indicios de que exista un grave riesgo o situación intolerable para el niño.

Obsérvese que el criterio de la mayoría con respecto a la posibilidad de que el tribunal recabe pruebas de oficio se apoya en la evolución ineluctable del derecho a reconocer a los niños como sujetos de derechos, contando con el derecho a la protección de riesgos y abusos, y por lo tanto, a la intervención del Estado en caso necesario, independientemente de las posturas de los padres. Mientras que la minoría parece aferrarse al criterio que lucha por la autonomía de los padres a criar a sus hijos con la menor intervención estatal posible, poniendo a los derechos de

52 Tesis II.3o.C.78 C, Semanario Judicial de la Federación y su Gaceta, Novena Época, tomo xxxI, marzo de 2010, p. 2928 (Registro no. 165071). "Convención sobre los Aspectos Civiles de la Sustracción Internacional de Menores. Carga de la prueba de quien se opone a la restitución de un menor. Del artículo 13 de la Convención sobre los Aspectos Civiles de la Sustracción Internacional de Menores se advierte que quien se oponga a la restitución de un menor tiene la obligación de demostrar las causas en que hace descansar esa oposición, de donde se sigue, que estas no son de aplicación automática y, en principio, a esta parte le corresponde la carga de la prueba. De manera excepcional, cuando el juzgador natural en salvaguarda del interés superior del niño, ordena recabar pruebas oficiosamente, deben estar vinculadas con alguna de las causas de oposición que enumera el citado artículo 13 y su desahogo debe ajustarse al plazo de seis semanas que el juzgador tiene para resolver, según lo indica el artículo 11 de la convención en comento".

Tesis II.3o.C.79 C, Semanario Judicial de la Federación y su Gaceta, Novena Época, tomo XxxI, marzo de 2010, p. 2959 (Registro N 165070). "Convención sobre los Aspectos Civiles de la Sustracción Internacional de Menores. El juez natural puede recabar oficiosamente pruebas en el procedimiento de solicitud de restitución de un menor si existe la presunción de la existencia de un grave riesgo que lo expone a un peligro físico o psíquico. El artículo 13, inciso b), de la Convención sobre los Aspectos Civiles de la Sustracción Internacional de Menores que autoriza al Estado requerido, en el procedimiento de solicitud de restitución, a de negar el traslado del menor cuando exista un grave riesgo que lo exponga a un peligro físico o psíquico o que de cualquier otra manera, ponga al menor en una situación intolerable, lleva a establecer que no basta un simple riesgo indeterminado, hipotético o de carácter general, sino que es necesario que existan indicios que soporten esa presunción y con base en esta, el Juez natural puede ordenar recabar oficiosamente pruebas". 
los niños en segundo plano. ${ }^{53}$ Para la autora, la primera es sin lugar a dudas el enfoque más adecuado de cara al futuro y a la evolución de los derechos de los niños.

Diversas preguntas podrán surgir en los casos concretos sobre si se deben recabar pruebas oficiosamente o cuándo debe únicamente basarse sobre las pruebas presentadas por las partes. Futuras decisiones darán posiblemente mayores pautas en la resolución de estos casos. Se espera que los tribunales valoren efectivamente las excepciones, fundando y motivando sus decisiones, sin caer en la tentación de hacer "un examen exhaustivo" de la situación del niño.

\section{Análisis de la jurisprudencia $X$ c. Letonia con respecto al artículo 3 del $\mathrm{CH} 1980$ y las medidas de protección para asegurar el regreso seguro del niño}

Este apartado comenzará con el estudio del artículo 3 del CH1980 y su análisis (o falta de un debido análisis por la mayoría) en $X$ c. Letonia. El artículo 3(2) establece que las decisiones judiciales y administrativas son fuentes de derechos de custodia para efectos del ch1980. No obstante, se desprende de este artículo que estas deben ser otorgadas con anterioridad al traslado o retención del niño. ${ }^{54}$

En opinión de la autora, en el caso $X$ c. Letonia el padre no contaba con derechos de custodia con arreglo al artículo 3 del cH1980, cuando el menor fue trasladado a Letonia desde Australia ${ }^{55}$ ni mucho menos ejerció efectivamente dichos derechos. Por consiguiente, la ausencia de este requisito provoca la inadmisibilidad o rechazo de la solicitud de restitución, lo que debería haber acontecido en el caso concreto.

\footnotetext{
53 Véase, Jane Fortin, Children's Rights and the Developing Law (Reino Unido: Cambridge University Press, 2009) 4-9, 550-552 y 749, para una explicación de estas teorías y las tendencias actuales.

54 Así lo indican los autores: Paul Beaumont y Peter McEleavy, The Hague Convention on International Child Abduction (Oxford: Oxford University Press, 2004) 52-57.

El sustento de esta afirmación radica en que el artículo 3 estipula que los derechos de custodia deben de ser efectivamente ejercidos. Lo que no sucedería si no existe una decisión judicial o administrativa antes del traslado o retención, y no existe otra base legal que confiera derechos de custodia.

55 Como lo indicó el juez Pinto de Albuquerque del TEDH en su opinión concurrente.
} 
Para ilustrar este punto, y como se indicó someramente al inicio, los hechos de $X$ c. Letonia relevantes a este apartado son los siguientes: los padres no estaban casados y el padre negó su responsabilidad parental hasta el último momento. ${ }^{56} \mathrm{La}$ negó ante las autoridades australianas aparentemente con el fin de que la madre recibiera beneficios por ser madre soltera; además, no aparecía como el padre biológico en el certificado de nacimiento del menor y nunca manifestó interés en invocar ese derecho. Al mismo tiempo, había concluido un contrato de arrendamiento con la madre para evitar que se supusiera que vivían juntos, y así obtener beneficios sociales. Asimismo, el menor nació cuando la madre aún se encontraba casada con otro hombre, de quien se divorció 9 meses después del nacimiento.

Sin embargo, a petición del padre, y alrededor de tres meses después del traslado, un tribunal australiano otorgó derechos de responsabilidad parental a ambos padres, sin realizar una prueba de paternidad. Dicha decisión, ex parte, surtió efectos de manera retroactiva al momento del nacimiento del menor. ${ }^{57} \mathrm{El}$ padre señaló en su petición que el paradero de la madre era "desconocido" en Letonia (y por lo tanto, se duda que se le haya debidamente notificado la demanda) ${ }^{58}$ Se indica que la solicitante aparentemente fue invitada para participar en la audiencia, ya sea en persona

56 Alegatos orales por parte del abogado de "X" ante el TEDH. Véanse también los hechos plasmados en TEDH, Statement of facts, Third Section, Application no. 27853/09, 23 March 2010, https://hudoc.echr.coe.int/eng\# \{“itemid”:[“003-3086023-3415688”]\}

57 Es importante indicar que no se activó el mecanismo previsto por el artículo 15 del CH1980 mediante el cual el tribunal letón solicita al juez australiano una certificación que acredite que el traslado o retención del menor era ilícito en el sentido del artículo 3 de este. Es más, el tribunal australiano indicó una frase que ahora es célebre, "however, it is not of course for me to say whether the child's presence in Latvia is the consequence of a wrongful removal or retention. With all due respect, it is for the Latvian judge to rule on that question." Traducción elaborada por la autora: Sin embargo, es evidente que no está en mí decir si la presencia del menor en Letonia es la consecuencia de un traslado o una retención ilícitos. Con todo respeto, recae en el juez letón zanjar dicha cuestión. Frase mencionada con admiración por el juez Dedov del TEDH en su opinión disidente en TEDH, Vladimir Ushakov v. Russia (Application no. 15122/17) [cita INCADAT: HC/E/ RU 1419] p. 31. Sin embargo, no coincidimos con dicha opinión del juez Dedov, ya que el Estado de la residencia habitual del menor es el mejor situado para determinar dicha cuestión.

58 TEDH, X c. Letonia, \13. Conforme al artículo 14 del CH1980 las autoridades judiciales o administrativas del Estado requerido podrán tener en cuenta directamente la legislación y las decisiones judiciales o administrativas, estén o no reconocidas formalmente en el 
o por teléfono, pero no estuvo presente, y que la solicitante no apeló esta decisión. Asimismo, la resolución se basó en pruebas poco fidedignas tales como correos electrónicos del padre. No se cuenta con una copia de la decisión del tribunal australiano, pero se observa que probablemente se infringieron las garantías de la madre al derecho de audiencia y defensa.

En efecto, la resolución australiana fue una verdadera "orden de persecución" (es decir, decisiones otorgadas con posterioridad al traslado o retención del niño). ${ }^{59}$ Como se puede observar de los hechos narrados con anterioridad, en estos procedimientos expost facto se considera muy superficialmente la posición jurídica del padre o madre desertora. Además, el objetivo del CH1980 es el restablecimiento del statu quo, lo que no es posible con una "orden de persecución".

Cabe destacar que no puede haber efectos retroactivos de responsabilidad parental para los efectos del CH1980. Sostener lo contrario, provocaría incertidumbre jurídica, dado que la persona encargada del cuidado principal del menor no puede reubicar su domicilio si existe esa posibilidad, aunque sea ínfima, que en el futuro a alguien se le otorguen derechos de custodia.

No es la intención del presente trabajo dar a entender una postura a favor de que el TEDH se inmiscuya en demasía en las decisiones de los tribunales de los Estados, al fin y al cabo, estos cuentan con un margen de apreciación. Sin embargo, pareciera que el tribunal de Letonia infringió los derechos y libertades protegidos por el CEDH al aceptar que el traslado era ilícito. No se puede evitar señalar que los tribunales de Letonia interpretaron de manera errónea el artículo 3 del cH1980, como lo indica el juez Pinto de Albuquerque en su opinión concurrente. ${ }^{60}$ El CH1980 no aplicaba, ya que el padre no contaba con derechos de custodia para efectos de este ni los había ejercido.

Es evidente que el TEDH no podía determinar si el proceso seguido ante el tribunal australiano en el que se otorgó responsabilidad parental era conforme al CEDH, dado que Australia no es Estado parte. Sin embargo, el TEDH sí hubiera podido determinar que Letonia infringió el CEDH al aceptar una orden visiblemente infundada donde la madre no

Estado de residencia habitual del menor. Se considera, sin embargo, que dichas decisiones deben estar ajustadas a las garantías esenciales de audiencia y debido proceso legal.

59 En inglés se le denomina "chasing order."

60 TEDH, X c. Letonia, opinión concurrente, 36-49. 
tuvo oportunidad de defenderse y era posterior al traslado. Como lo ha indicado el TEDH en relación a la ejecución de decisiones provenientes de Estados no miembros, el proceso en dicho Estado debe estar regido por el principio de contradicción, las partes deben tener la posibilidad de ser representadas por un abogado, conocimiento de las pruebas y la posibilidad de refutarlas. ${ }^{61}$

En lo referente a las medidas de protección para asegurar un retorno seguro del niño cabe señalar lo siguiente. En el seno de la Conferencia de La Haya, se ha manifestado una preocupación por la falta de medidas de protección, se ha llegado a proponer, incluso, la redacción de un protocolo al CH1980 (que no prosperó). ${ }^{62}$ Con esta sentencia, el TEDH ha asentado la necesidad de proveer medidas de protección en sus 47 Estados miembros al restituir un menor a su país de residencia habitual. ${ }^{63}$ Esto nos parece un gran avance ya que es indispensable para el correcto funcionamiento del CH1980 —en particular en los Estados que aún no son parte del Convenio de La Haya de 19 de octubre de 1996 Relativo a la Competencia, la Ley Aplicable, el Reconocimiento, la Ejecución y la Cooperación en materia de Responsabilidad Parentaly de Medidas de Protección de los Niños (CH1996)—.

Para ilustrar este punto en el caso $X$ c. Letonia, dicho país podría haber acordado, entre otras, las siguientes medidas de protección: el padre pudiera haberse comprometido a cubrir los costos de viaje de la madre y el menor, a ofrecer un lugar para que la madre residiera con el menor mientras se resolvía el procedimiento de custodia, alimentos, asegurarse de que la madre pudiera participar en el litigio de custodia (con representación legal o defensoría de oficio), así como ejercer derechos de visita con respecto al menor mientras durara el procedimiento, y finalmente,

\footnotetext{
61 A manera de analogía, véase en ese sentido, TEDH, Pellegrini v. Italy, no. 30882/96, \$40-48, ECHR 2001.

${ }^{62}$ Conferencia de La Haya de Derecho Internacional Privado, "Conclusions and Recommendations of Part I and Part II of the Special Commission on the Practical Operation of the 1980 Child Abduction Convention and the 1996 Child Protection Convention and a Report of Part II of the Meeting," de abril de 2012, 6-7, https://assets.hcch.net/ upload/wop/concl28-34sc6_en.pdf

63 TEDH, X c. Letonia, $\$ 108$ : "the courts must satisfy themselves that adequate safeguards are convincingly provided in that country, and, in the event of unknown risk, that tangible protection measures are put in place." Traducción de la autora: Los tribunales deben satisfacerse con que existen medidas adecuadas en ese país y en caso de que exista un riesgo desconocido, se deberán implementar medidas de protección tangibles.
} 
concederle una orden de alejamiento en contra del padre durante el transcurso del procedimiento de custodia.

Sin embargo, se debe destacar que el reconocimiento y ejecución de dichas medidas de protección en un Estado requirente es aún bastante complicado y nebuloso. Lo anterior a menos de que ambos Estados sean parte del CH1996. Lo que acontece en el caso específico, pues tanto Australia como Letonia son Estados contratantes desde inicios del siglo XXI; desafortunadamente no se invocó este tratado en el caso concreto.

\section{Análisis de sentencias recientes del TEDH a la luz de $X$ c. Letonia}

Debido a las limitantes de espacio, no se pretende hacer un estudio exhaustivo de las sentencias del TEDH emitidas con posterioridad al asunto $X c$. Letonia. Se hará énfasis en tres sentencias recientes de este que se consideran dignas de mencionarse por su relevancia y actualidad. Dos de ellas se encuentran en consonancia con el asunto $X$. c. Letonia y sus principios, y confirman por lo tanto, el entendimiento presentado del CH1980, así como su interacción con los tratados de derechos humanos. Una tercera sentencia pareciera no ser acorde a uno de los principios establecidos en $X$ c. Letonia, pero el resultado alcanzado pareciera ser correcto.

La primera sentencia fue dictada el primero de marzo de 2016 por la cuarta sección del TEDH, y se refiere al asunto K.J. c. Polonia. ${ }^{64}$ En dicho asunto se consideró si Polonia había infringido el artículo 8 del CEDH por haber denegado el retorno de un menor de conformidad con el artículo 13(1)(b) del CH1980. Este caso fue uno intracomunitario de la Unión Europea y por tanto, aplicó el CH1980 y el Reglamento (CE) no 2201/2003: competencia, reconocimiento y ejecución de resoluciones judiciales en materia matrimonial $y$ de responsabilidad parental (en lo subsiguiente, Bruselas II bis).

Los hechos del caso son los siguientes: un matrimonio de polacos residía en el Reino Unido y había tenido una hija en dicho país. Después de unas vacaciones, la madre retuvo a la menor en Polonia y rehusó retornarla al Reino Unido. Durante el procedimiento, la madre alegó que lo hizo debido a que la relación con el padre se había deteriorado y temía que la menor no pudiera salir del Reino Unido. En particular, alegó que la menor estaría expuesta a una situación intolerable si regresase a dicho

64 TEDH, K.J. v. Poland (Application no. 30813/14) [cita INCADAT: HC/E/PL 1348]. 
país, debido a que por su edad sería separada de la madre la cual tenía el cuidado principal de la menor, y aún si la madre regresase no sería del interés de la menor porque la madre lo haría en contra de su voluntad (sin mencionar ninguna causa de peso).

Los tribunales polacos aceptaron dichos argumentos y rechazaron la restitución de la menor sin realmente sopesar el informe en el que se indicaba que la menor estaba en buen estado psicológico y físico, estaba emocionalmente vinculada a ambos padres, y consideraba que Polonia y el Reino Unido eran su hogar. El argumento relativo a la separación de la niña de su madre sin una causa válida, o haciendo referencia únicamente a los inconvenientes prácticos de un retorno, no constituye una excepción en virtud del artículo 13(1)(b) del cH1980 de conformidad con la jurisprudencia dimanante del TEDH y los Estados contratantes. ${ }^{65}$

Asimismo, existió una demora importante en la resolución de dicho asunto. Por consiguiente, el Tribunal Europeo concluyó acertadamente, que Polonia infringió la garantía consagrada en el artículo 8 del CEDH, concerniente a su derecho al respeto de la vida familiar, y condenó a Polonia a una cantidad monetaria.

La segunda sentencia se refiere al caso Vladimir Ushakov c. Rusia, anteriormente mencionada, ${ }^{66}$ la cual fue dictada por la tercera sección del TEDH el 18 de junio de 2019. Dicho asunto analizó si existía violación del artículo 8 del CEDH por parte de las autoridades rusas al rechazar el retorno de una menor en base al artículo 13(1)(b) del cH1980.

Los hechos del caso son los siguientes: un matrimonio que residía en Finlandia tuvo una hija. El padre contaba con un permiso de residencia permanente en Finlandia mientras que la madre y la menor eran de nacionalidad rusa, y contaban con un permiso de residencia temporal en Finlandia. Los problemas conyugales iniciaron cuando la madre tuvo un ataque cerebrovascular y fue hospitalizada, a causa del cual perdió parcialmente la movilidad de una mano y una pierna. La madre tuvo que

\footnotetext{
65 Véase Xc. Letonia, $\mathbb{1} 116$.

Se ha señalado con respecto al argumento de la separación del menor de la madre si ella se opone a regresar, que esta debe demostrar que tiene efectivamente dificultades para volver y no es solo un capricho.

Véase C. v. C. (Minor: Abduction: Rights of Custody Abroad) [1989] 1 WLR 654 [cita INCADAT: HC/E/UKe 34] y más recientemente Re E. (Children) (Abduction: Custody Appeal) [2011] UKSC 27, [2012] 1 A.C. 144 [cita INCADAT: HC/E/UKe 1068] (Reino Unido).

${ }_{66}$ Véase nota a pie de página 57.
}

ACDI, Bogotá, ISSN: 2027-1131/ISSNe: 2145-4493, Vol. 13, pp. 209-249, 2020 
viajar a Rusia para recibir tratamiento médico. La niña se quedó con el padre, el cual luego la trasladó a Noruega con la abuela paterna. Al llegar a Finlandia, la madre inició un procedimiento de restitución de niños, pero el padre de manera voluntaria regresó la niña a Finlandia.

Posteriormente, los tribunales finlandeses se pronunciaron en dos ocasiones, en primera instancia y apelación sobre la custodia, concluyeron que la menor residiría con el padre, debido al estado de salud de la madre, pero ambos tendrían la custodia compartida. Entre tanto, mientras la apelación estaba pendiente de ser resuelta, la madre trasladó a la menor a Rusia e informó al padre que no iban a regresar. El padre inició un procedimiento de restitución de la menor, el tribunal de primera instancia ruso ordenó el retorno pero en apelación el tribunal de la ciudad de San Petersburgo rechazó la petición de retorno. En particular, dicho tribunal resolvió que Finlandia no era el Estado de la residencia habitual de la menor, y que en vista de los numerosos problemas de salud de la menor, no sería oportuno trasladarla a Finlandia.

El TEDH determinó que el tribunal de apelación ruso no consideró ni fundamentó debidamente las razones por las cuales rechazó la restitución de la menor. En particular, no se consideró ni motivó debidamente el estado de salud de la menor, así como cualquier circunstancia argumentada por la madre, y su evaluación a la luz del artículo 8 del CEDH. En particular, no se incluyeron en la decisión de dicho tribunal la totalidad de los problemas médicos de la menor ni se señaló qué tratamiento médico era necesario o si ese tratamiento estaba disponible en Finlandia.

Lo anterior, en opinión de la autora, es conforme al criterio de $X$ c. Letonia que requiere que los elementos o circunstancias que puedan constituir excepciones en virtud de los artículos 12, 13 y 20 del CH1980 deban ser debidamente considerados por los tribunales, los cuales deberán motivar sus resoluciones. Además, lo anterior deberá ser analizado a la luz del artículo 8 del CEDH. En el presente caso, la decisión rusa no estuvo debidamente motivada como se comentó anteriormente.

De manera acertada, el TEDH indicó que si bien pudieron existir causas que justificaran la invocación del artículo 13(1)(b) del cH1980, estas no fueron mencionadas por las autoridades nacionales y no era el papel del TEDH suplantar su razonamiento a dichas autoridades. ${ }^{67}$

67 Inevitablemente, existe divergencia en el seno del tribunal en si hubo o no violación del artículo 8 del CEDH, y si dicha sentencia fue conforme a $X$ c. Letonia. En este sentido, 
Efectivamente, se observa una posible negligencia por parte de las autoridades rusas al no mencionar la posible dificultad o imposibilidad de la madre de ingresar a Finlandia para ejercer la custodia compartida, ya que tanto el permiso de residencia de la madre como el de la menor habían expirado desde 2014 (la menor) y 2015 (la madre). Asimismo, se debería haber planteado si la madre podría viajar a Finlandia de manera regular para ejercer sus derechos o si esto hubiera sido imposible debido a sus problemas médicos.

La tercera sentencia, objeto de estudio en el presente apartado, se dictó el primero de febrero de 2018 por la primera sección del TEDH, y se refiere al asunto M.K. c. Grecia. ${ }^{68} \mathrm{~A}$ diferencia de las dos sentencias referidas en este apartado, esta ha sido controversial como se explicará más adelante. En dicho asunto se analizó si Grecia había violado el artículo 8 del CEDH, debido a la falta de ejecución de una decisión griega de retorno de un menor a Francia. ${ }^{69}$ Este caso fue un intracomunitario de la UE y por tanto, aplicó el CH1980 y el Reglamento Bruselas II bis. En particular, se observa que este caso intentó encontrar un equilibrio entre los derechos de los niños y las salvaguardas procesales y la certidumbre jurídica.

Los hechos del caso son los siguientes: una ciudadana rumana se divorció de su pareja en Grecia, dicho matrimonio había tenido dos niños. Al tener que desplazarse a Francia por razones de trabajo, la madre confió a sus dos hijos al cuidado de la abuela materna en Grecia. Posteriormente, al ejercer el derecho de visita, el padre rehusó regresar a los menores con la abuela e interpuso una demanda, pero al final el tribunal consideró

el voto disidente del juez Dedov de la Federación Rusa (advirtamos que es un caso contra Rusia y este es el juez ruso) incluso cuestiona el CH1980 y menciona sus deficiencias sistemáticas con respecto a las partes vulnerables. Sin embargo, en nuestra opinión si se hubieran invocado los alegatos adecuados, el resultado hubiera sido que Rusia no hubiera violado el artículo 8 del CEDH. Véase, Vladimir Ushakov v. Russia, 28-32.

68 TEDH, M.K. c. Grèce (Requête n ${ }^{\circ}$ 51312/16) [no es un caso INCADAT].

69 En dicho caso, no se activó el mecanismo de los artículos 11(8) y 42 del Reglamento Bruselas II bis, denominado "overriding mechanism" o "retour nonobstant", debido a que la sentencia griega era de retorno (y no denegando el retorno). Asimismo, no existía una decisión judicial francesa ordenando formalmente el retorno del menor en los términos del Reglamento II bis. Solamente se puede suponer qué hubiera pasado si se hubiese denegado el retorno por las autoridades griegas. El Reglamento II bis obliga a escuchar al menor antes de aplicar el mecanismo "retour nonobstant" y nos preguntamos si un tribunal francés hubiera ordenado el retorno a pesar de las objeciones del adolescente. Nosotros suponemos que no hubiera sido ordenado. 
que los menores deberían de acompañar a su madre a Francia. La madre logró llevarse a uno de sus hijos (denominado A y objeto de este procedimiento) a Francia mientras que el otro niño se quedó en Grecia con su padre. Después de unas vacaciones en Grecia, el padre rehusó retornar al menor "A", aun si este había vivido alrededor de tres años en Francia con su madre.

Dicho asunto es complejo, ya que existieron múltiples instancias civiles y penales interpuestas por ambas partes, tanto en Francia como en Grecia, que complicaron el caso en extremo. Es evidente que procedimientos penales obstaculizan el funcionamiento del CH1980, lo cual se hizo patente en este caso. El TEDH concluyó que las autoridades griegas tomaron las medidas que se podían razonablemente exigir de ellas, en vista del margen de apreciación con el que contaban, para cumplir con sus obligaciones positivas que se desprenden del artículo 8 del CEDH, y por tanto, no hubo violación de dicho artículo.

Cabe destacar que el voto disidente de la jueza finlandesa Koskelo ha considerado que dicha sentencia no es conforme al precedente de $X$ c. Letonia y lo distorsiona, por ello critica dicha sentencia severamente. ${ }^{70}$ Se coincide con la jueza Koskelo en que la sentencia de la mayoría omitió principios consagrados en X.c Letonia, en particular el párrafo 105, el cual indica que los jueces nacionales no están obligados a hacer un examen exhaustivo de la situación familiar. $\mathrm{Y}$ al contrario reitera que se debe hacer un examen exhaustivo, tal y como lo sugería el asunto Neulinger. ${ }^{71}$

Sin embargo, nos parece que dicho voto disidente adopta una postura legalista y algo rigorista. En particular, no coincidimos con la aseveración que

while the child's best interests are a primary consideration, they must as such operate within the framework of proper and lawful procedures. A child's best interests cannot serve as justification for the enforcement authorities to re-examine the substance of issues which have already been the subject of final adjudication by the competent courts. ${ }^{72}$

\footnotetext{
70 Voto disidente de la jueza Koskelo en M.K. c. Grèce, 27.

71 Véase, párrafo 75 del asunto M.K. c. Grèce.

72 Voto disidente de la jueza Koskelo en M.K. c. Grèce, 32, \20. Traducción elaborada por la autora: Si bien el interés superior del menor es de una consideración primordial, dicho interés debe de operar en el marco de procedimientos legales y apropiados. Las
} 
Entendemos que desde una perspectiva intracomunitaria, es decir en el seno de la UE, la no ejecución de una decisión de retorno puede ser controversial y constituir una afrenta a la confianza mutua entre sus Estados miembros. No obstante, debe recordarse que a fin de salvaguardar las garantías del artículo 8 del CEDH, se debe efectuar un equilibro entre los intereses de los padres, del menor y del orden público.

Además de lo referido anteriormente, se considera que existen dos razones importantes en el análisis presentado. Primero, es indudable que los menores cuentan con el derecho a expresar su opinión en todos los asuntos que les afecten, sin importar en qué instancia o estado se encuentren dichos asuntos o procedimientos, y que dicha opinión sea debidamente tomada en cuenta en función de la edad y madurez del niño, ${ }^{73}$ derecho que se encuentra consagrado en el artículo 12 de la Convención de Naciones Unidas sobre los Derechos del Niño, así como en otros instrumentos europeos. ${ }^{74}$ En el presente caso, las autoridades griegas tomaron precisamente en cuenta la opinión del menor, ya que este contaba con trece años al momento del retorno.

Segundo, cuando existe una oposición severa del menor a ser retornado, como en el caso en concreto, se ha observado que un retorno de niños o adolescentes usando medidas coercitivas puede llevar a la imposibilidad de la ejecución de la sentencia en la práctica, ya que los menores pueden impedir el despegue del avión o causar que se aborte el vuelo. ${ }^{75}$ Posteriormente, también puede suceder que sea imposible la convivencia

autoridades encargadas de la ejecución no pueden excusarse en base al interés superior del menor para reexaminar a fondo temas que ya han sido zanjados de manera definitiva por los tribunales competentes.

73 Véase Conclusión y Recomendaciones de la Comisión Especial de 2011, no. 50 que reza así: "La Comisión Especial celebra el apoyo abrumador de la posibilidad de brindarles a los niños, según su edad y grado de madurez, la oportunidad de ser escuchados en el marco del proceso de restitución en virtud del Convenio de 1980 independientemente del hecho de que se haya planteado una excepción en virtud del artículo 13(2). [...]"

74 Véase M.K. c. Grèce, \ 91.

75 Véanse los asuntos del Reino Unido (Inglaterra y Gales) en los cuales no pudieron ser ejecutados por la objeción del menor o menores: Re M. (A Minor) (Child Abduction) [1994] 1 FLR 390 [cita INCADAT: HC/E/UKe 56]; T.B. v. J.B. (Abduction: Grave Risk of Harm) [2001] 2 FLR 515 [cita INCADAT: HC/E/UKe 419]; Re F. (Hague Convention: Child's Objections) [2006] FamCA 685, (2006) FLC 93-277; 36 Fam LR 183 [cita INCADAT: HC/E/ AU 864]. 
entre el menor retornado y el padre o madre solicitante, debido a lo abrupto y violento del retorno. ${ }^{76}$

Si bien ha existido controversia en torno a esta decisión en el contexto de la UE y se ha manifestado preocupación, de manera informal y extrajudicial, por parte de un miembro del Tribunal de Justicia de la Unión Europea, ${ }^{77}$ se considera en este texto que dicha sentencia llegó a la conclusión correcta. Dicha conclusión se puede justificar sin la necesidad de omitir principios consagrados en $X$ c. Letonia, ya que no es necesario hacer un examen exhaustivo de la situación familiar y del niño para llegar a la conclusión referida. En efecto, es un principio inalienable de los niños el expresar su opinión y que dicha opinión sea tomada en cuenta en función de su edad y madurez. Es indudable que los niños son sujetos de derechos y han dejado de ser considerados como "objetos" que deban ser meramente transferidos de un lugar a otro. Además, el CH1980 tiene como principio rector el interés superior del menor tanto general (es decir, evitar sustracciones y prever un mecanismo para el retorno del menor), como en concreto cuando se invoquen excepciones. El CH1980 se centra, por tanto, en el menor y no es un mero mecanismo para resolver la situación conflictiva entre los padres.

En vista de lo anterior, todo parece indicar que por lo general las sentencias posteriores del TEDH han confirmado el entendimiento expuesto del CH1980 y la naturaleza restringida de las excepciones, por lo que son igualmente bienvenidas.

\footnotetext{
76 A manera de analogía, véase el caso del niño Zulu: Jojo Moyes, "Zulu boy allowed to stay in Britain with foster mother," Independent, 26 February 1997, https://www.independent.co.uk/news/zulu-boy-allowed-to-stay-in-britain-with-foster-mother-1280636.html

77 Conversación con el juez finlandés del Tribunal de Justicia de la Unión Europea, profesor Allan Rosas el 22 de mayo de 2019 en Luxemburgo en el marco de un seminario de investigación intitulado Enforcement Challenges in Multi-Level Regulatory Systems: Mapping the Landscapes, organizado por el Max Planck Institute Luxemburg for International, European and Regulatory Procedural Law.

También se ha manifestado preocupación en otros círculos, véase por ejemplo Sara Lembrechts M.K. v. Greece - Implementing children's rights in legal proceedings following an international parental abduction, Strasbourg observers, https://strasbourgobservers.com/category/ cases/m-k-v-greece/
} 


\section{Conclusiones}

Es indudable que el papel que ha desempeñado el TEDH en la interpretación del CH1980 ha sido controversial. Lo anterior se debe a la incertidumbre que ha generado por las múltiples sentencias que han emitido tanto las secciones como la Gran Sala, así como la dificultad de dilucidar sus alcances concretos.

Si bien, a consideración de la autora, en un inicio — desde Neulingerlas sentencias emitidas por el TEDH fueron perjudiciales para el CH1980, porque desvirtuaron su objetivo, la sentencia de X c. Letonia (Gran Sala) disipó las dudas sobre los principios regidores de este en relación con las garantías tuteladas por el CEDH, y buscó una interpretación armónica entre ambos tratados.

Estos deben coexistir y ser interpretados de manera armónica. Una interpretación aislada del cH1980, sin referencia a los tratados aplicables sobre derechos humanos, se ha convertido en una práctica de antaño, y es por ello, que nos encontramos en una etapa evolutiva de este. Como lo indica el TEDH, el artículo 8 del CEDH debe leerse a la luz de los requisitos del CH1980, y de conformidad con las reglas y principios de derecho internacional aplicables en la relaciones entre los Estados contratantes. ${ }^{78}$

Desde el análisis presentado también se propone lo contrario: el CH1980 debe leerse a la luz de los principios del CEDH (por lo menos en los Estados parte de este), los principios de derecho internacional y de la Convención de Naciones Unidas de 1989 sobre los Derechos del Niño. ${ }^{79}$ Se considera que los tratados de derechos humanos que han sido

78 TEDH, X c. Letonia, \ 93-94.

79 Asimismo, surge otra pregunta frente a si esta afirmación implica una aceptación de que existen interpretaciones diferentes del CH1980 para Estados no contratantes del CEDH. La respuesta a dicha interrogante debe ser negativa. Considero que el CH1980 deberá interpretarse conforme a los tratados de derechos humanos aplicables, sobre todo la Convención de Naciones Unidas de 1989 sobre los Derechos del Niño, que es un tratado universal. El CH1980 es complementario a dicho tratado de derechos humanos, aun si fue elaborado anteriormente. En Latinoamérica, será la Convención Americana sobre Derechos Humanos (Pacto de San José). En particular, es relevante el artículo 19 "Derechos del Niño: Todo niño tiene derecho a las medidas de protección que su condición de menor requieren por parte de su familia, de la sociedad y del Estado". 
generalmente adoptados tienen como fin proteger los mismos derechos que el CH1980 por lo que no deberían causar interpretaciones contradictorias. ${ }^{80}$

A continuación, se exponen los principales criterios de $X$ c. Letonia. Primero, que el artículo 8 del CEDH debe leerse a la luz de los requisitos del CH1980 y de conformidad con las reglas y principios de derecho internacional aplicable. Por consiguiente, dichos tratados no tutelan derechos o garantías irreconciliables. De esta manera, el TEDH armoniza en 47 Estados las pautas a seguir en casos de sustracción de menores; esto es, a mi ver, uno de los grandes logros de este tribunal.

Segundo, el TEDH aclara que el párrafo 139 de la sentencia Neulinger no establece un criterio vinculante para los tribunales nacionales ni fija parámetros que deban ser cumplidos por estos, para una interpretación armónica del CEDH y el CH1980. Por consiguiente, se reitera que no se debe hacer un examen exhaustivo de la totalidad de la situación familiary de una serie de elementos relativos al caso especifico de sustracción internacional de menores. A fin de cumplir con las condiciones del TEDH especificadas en el asunto $X c$. Letonia, el tribunal requerido solamente deberá considerar verdaderamente los elementos que puedan constituir una excepción en virtud de los artículos 12, 13 y 20 del CH1980, en particular cuando se invoquen por una de las partes, y motivar su decisión; estos elementos deberán ser evaluados a la luz del artículo 8 del CEDH, a fin de permitir al TEDH verificar que dichos elementos fueron objeto de un examen efectivo y por tanto lo facultará

80 En este sentido, coincidimos con la opinión del honorable ex-ministro de la Suprema Corte de Justicia de Uruguay entre 2012 y 2017, Ricardo César Pérez Manrique, recientemente electo juez de la Corte Interamericana de Derechos Humanos de la Organización de Estados Americanos (OEA), que así lo plasmó en su artículo.

Véase, Ricardo C. Pérez Manrique, "Sustracción internacional de niños y derechos humanos", en Cuestiones Complejas en los Procesos de Restitución Internacional de Niños en Latinoamérica, coordinado por Lázaro Tenorio Godínez, Nieve Rubaja, Florencia Castro (México: Porrúa, 2017), 16-18.

Asimismo, coincidimos con algunas de las conclusiones expuestas por la profesora Elena Rodríguez Pineau en su artículo sobre esta temática. Véase Elena Rodríguez Pineau, "El adecuado equilibrio entre el respeto del CEDH y la aplicación del Convenio de La Haya de 1980 (nota a X c Letonia)", Revista General de Derecho Europeo, 33 (2014), 18-22.

Desafortunadamente, conocimos dicho artículo de manera tardía cuando ya estábamos concluyendo la redacción final de este trabajo. 
a la supervisión europea que le fue encomendada, ya que su objetivo no es sustituir a los jueces nacionales. ${ }^{81}$

Tercero, desde la perspectiva procesal parece relevante recalcar dos criterios. Por un lado, el TEDH ha asentado la necesidad de proveer medidas de protección al restituir a un menor a su país de residencia habitual. Por otro, ha indicado la necesidad de recabar pruebas de oficio cuando se invoquen las excepciones, sobre todo el artículo 13, y así lo permita el derecho interno del Estado requerido. Si bien otorgar protección a los más vulnerables de oficio, como a los niños, es discutible en algunos foros, sobre todo en asuntos de derecho de familia, dicha postura del TEDH es un gran avance en la protección de la niñez. Esta política tiene como médula la percepción del Estado ante la sociedad, por lo que variará dependiendo del Estado interviniente. Dicho esto, si el derecho nacional no permite recabar pruebas de oficio, dudamos que el TEDH estime que los derechos tutelados en el CEDH hayan sido infringidos dado que no existiría fundamento jurídico para hacerlo.

Cuarto, es menos probable, sin embargo, que el TEDH ordene un retorno del niño, o bien que considere a un Estado parte como infringiendo el CEDH a menos de que ordene un retorno del niño, debido al posible transcurso del tiempo desde el traslado o retención (ya que el principio de celeridad es de suma importancia para el debido funcionamiento del CH1980), ya que se debieron agotar todas las instancias correspondientes, y el niño probablemente se encuentra integrado en su nuevo ambiente. Además de que en caso de constatarse una violación, el TEDH generalmente se restringe, en este tema, a otorgar una compensación monetaria a cargo del Estado demandado (así como el reembolso de los gastos incurridos en caso de ser procedentes).

Finalmente, se observa que, tras casi seis años del fallo de la Gran Sala en $X$ c. Letonia, el TEDH viene manteniendo los principios plasmados en dicha sentencia. De la investigación presentada de las sentencias recientes del TEDH, solo se advirtió una sentencia que podría ser no conforme a los principios de X. c. Letonia, el asunto M.K. c. Grecia. Sin embargo, se considera que la conclusión alcanzada en dicha sentencia fue correcta. Por lo que se augura que la interpretación armónica del CEDH y del CH1980 perdurará en el tiempo.

81 TEDH, Xc. Letonia, $\mathbb{S} 107$. Texto original en inglés: "whose task is not to take the place of the national courts, to carry out the European supervision entrusted to it." 


\section{References}

Beaumont, Paul R. "The Jurisprudence of the European Court of Human Rights and the European Court of Justice on the Hague Convention on International Child Abduction.” Recueil des cours 335, (2008): 9-103.

Beaumont, Paul, Trimmings, Katarina, Walker Lara, \& Jayne Holliday. "Child Abduction: Recent jurisprudence of the European Court of Human Rights," International and Comparative Law Quarterly 64, no. 1 (2015): 39-63. https:/ / doi.org/10.1017/S0020589314000566

Beaumont, Paul \& Walker Lara. "Post Neulinger Case Law of the European Court of Human Rights on the Hague Child Abduction Convention." En A Commitment to Private International Law, Essays in honour of Hans van Loon. Reino Unido: Intersentia, 2013.

Beaumont, Paul \& McEleavy, Peter. The Hague Convention on International Child Abduction. Oxford: Oxford University Press, 2004.

Boiché, Alexandre. "Enlèvement International d'enfants: la Cour Européenne des Droits de l'homme revient sur sa jurisprudence Neulinger". AJ Famille, Dalloz (2014): 58-60.

Buyse, Antoine. "X v Latvia Child Abduction Grand Chamber Judgment", ECHR blog. Recuperado de http://echrblog.blogspot.com/2013/12/xv-latvia-child-abduction-grand.html

Crumley, Brett. "X v Latvia: Creative Harmony, Fortunate Result", Oxford Human Rights Hub. Recuperado de http://ohrh.law.ox.ac. uk/x-v-latvia-creative-harmony-fortunate-result/

Detrick, Sharon. A Commentary on the United Nations Convention on the Rights of the Child. The Hague: Kluwer Law International, 1999.

Fortin, Jane. Children's Rights and the Developing Law. Reino Unido: Cambridge University Press, 2009.

Jacobs, Francis G. The European Convention on Human Rights. Guildford: Oxford University Press, 1975.

van Loon, Hans. Interaction Between Recent Case-law of the European Court of Human Rights and the Hague Convenion of 25 October 1980 on the Civil Aspects of International Child Abduction, 17 de marzo de 2011. Recuperado de http://www.hcch.net/upload/coe2011.pdf

McEleavy, Peter, "The European Court of Human Rights and the Hague Child Abduction Convention: Prioritising Return or Reflection?" Netherlands International Law Review 62, (2015): 365-405. https:// doi.org/10.1007/s40802-015-0040-z 
Moyes, Jojo. "Zulu boy allowed to stay in Britain with foster mother", Independent, 26 February 1997. Recuperado de https://www.independent.co.uk/news / zulu-boy-allowed-to-stay-in-britain-withfoster-mother-1280636.html

Neulinger, Isabelle. Jamais vous n'aurez mon fils. Paris: Jourdan PixL, 2015. Lembrechts Sara. "M.K. v. Greece - Implementing children's rights in legal proceedings following an international parental abduction”, Strasbourg observers. Recuperado de https://strasbourgobservers. com/category/cases/m-k-v-greece/

Lindhorst, Taryn \& Edleson, Jeffrey L. Battered Women, their Children, and International Law - the Unintended Consequences of the Hague Child Abduction Convention. Boston: Northeastern University Press, 2012.

Pérez Manrique, Ricardo C. "Sustracción Internacional de Niños y Derechos Humanos". En Cuestiones complejas en los procesos de restitución internacional de niños en Latinoamérica, coordinado por Lázaro Tenorio Godínez, Nieve Rubaja, Florencia Castro. México: Porrúa, 2017.

Requejo Isidro, Marta. "El derecho al respeto a la vida privada y familiar y el secuestro internacional de menores. Los estados miembros de la UE ante el TEDH: estado de la cuestión (2016)". Anuario de los cursos de derechos humanos de Donostia-San Sebastián 16, (2016): 283-320.

Rodríguez Pineau, Elena. "El adecuado equilibrio entre el respeto del CEDH y la aplicación del Convenio de La Haya de 1980 (nota a X c Letonia)", Revista General de Derecho Europeo, no. 33 (2014): 1-22.

Schabas, William A. The European Convention on Human Rights. Oxford: Oxford University Press, 2015.

Schuz, Rhona. The Hague Child Abduction Convention - A Critical Analysis. Oxford: Hart Publishing, 2013.

Walker, Lara. "The Impact of the Hague Abduction Convention on the Rights of the Family in the Case-law of the European Court of Human Rights and the UN Human Rights Committee: The Danger of Neulinger", Journal of Private International Law 6, no. 3 (2010): 649-682.

\section{Documentos oficiales}

Conferencia de La Haya de Derecho Internacional Privado, Conclusiones y Recomendaciones de las reuniones en 2011, 2012 y 2017 de la Comisión Especial sobre el funcionamiento práctico del Convenio de 1980 sobre Sustracción Internacional de Menores y del 
Convenio de 1996 sobre Protección de Niños, y sus informes. Recuperado de https://assets.hcch.net/docs/edce6628-3a76-4be8a092-437837a49bef.pdf (reunión de 2017), https:/ / assets.hcch.net/ upload/wop/concl28-34sc6_en.pdf (reunión de 2012) y https:/ / assets.hcch.net/upload/wop/abduct2012pd14e.pdf (reunión de 2011).

Nigel Lowe, Victoria Stephens, Part I - A statistical analysis of applications made in 2015 under the Hague Convention of 25 October 1980 on the Civil Aspects of International Child Abduction -Global report - provisional edition, pending the completion of the French version, Conferencia de La Haya de Derecho Internacional Privado, Documento Preliminar No $11 \mathrm{~A}$ de febrero de 2018. Recuperado de https:/ / assets.hcch.net/docs/d0b285f15f59-41a6-ad83-8b5cf7a784ce.pdf.

TEDH. Annual Report 2017 and 2018 of the European Court of Human Rights, Council of Europe, (Chapter 6). Recuperado de https:/ / echr.coe.int/ Documents/Annual_report_2017_ENG.pdf y https://echr.coe. int/Documents/Annual_report_2018_ENG.pdf (consultado el 26 de marzo de 2019).

TEDH. Factsheet Extra-territorial jurisdiction of States Parties to the European Convention on Human Rights, July 2018. Recuperado de https: / /www. echr.coe.int/Documents/FS_Extra-territorial_jurisdiction_ENG. pdf (consultado el 26 de marzo de 2019).

TEDH. Press release issued by the Registrar of the Court, no. 377 of 28 April 2011. Recuperado de https://hudoc.echr.coe.int/eng\#\{\%22ite $\operatorname{mid} \% 22:[\% 22003-3520146-3971634 \% 22]$ \} (consultado el 26 de marzo de 2019).

TEDH. The general practice followed by the panel of the grand chamber when deciding on requests for referral in accordance with article 43 of the convention (October 2011). Recuperado de https://www.echr.coe.int/Documents/ Note_GC_ENG.pdf

\section{Jurisprudencia del Tribunal Europeo de Derechos Humanos}

TEDH. Deak v. Romania and the United Kingdom (Application no. 19055/05) [cita INCADAT: HC/E/UKe 974].

TEDH. Karrerv. Romania (Application no. 16965/10) [cita INCADAT: HC/E/ RO 1149]. 
TEDH. K.J. v. Poland (Application no. 30813/14) [cita INCADAT: HC/E/ PL 1348].

TEDH. Maumousseau and Washington v. France (Application No 39388/05) [cita INCADAT: HC/E/FR 942].

TEDH. M.K. c. Grèce (Requête no. 51312/16).

TEDH. MR and LR v. Estonia (Application no. 13420/12) (declarado inadmisible) [cita INCADAT: HC/E/EE 1177].

TEDH. Neulinger and Shuruk v. Switzerland (Application no. 41615/07) [cita INCADAT: HC/E/CH 1001].

TEDH. Neulinger and Shuruk v. Switzerland (Application no. 41615/07), Grand Chamber [caso INCADAT: HC/E/CH 1323].

TEDH. Pellegrini v. Italy, (Application no. 30882/96), ECHR 2001 [no es un caso INCADAT].

TEDH. P.P. v. Poland (Application no. 8677/03) [cita InCADAT: HC/E/ PL 941].

TEDH. Raban v. Romania (Application no. 25437/08) [cita INCADAT: HC/E/ RO 1330].

TEDH. Šneersone and Kampanella v. Italy (Application no. 14737/09) [cita INCADAT: HC/E/LV 1152].

TEDH. Statement of facts, Third Section, Application no. 27853/09, 23 March 2010. Recuperado de https://hudoc.echr.coe.int/eng\#\{“i temid":[“003-3086023-3415688”]\}

TEDH. Vladimir Ushakovv v. Russia (Application no. 15122/17) [cita INCADAT: $\mathrm{HC} / \mathrm{E} / \mathrm{RU}$ 1419].

TEDH. X v. Latvia (Application no. 27853/09), Grand Chamber [cita INCADAT: HC/E/LV 1234].

Jurisprudencia de varios Estados

Estados Unidos de América. Abbott v. Abbott, 130 S. Ct. 1983 (2010) [cita INCADAT: HC/E/USf 1029].

México, Gaceta del Semanario Judicial de la Federación. Tesis III.2o.C.71 C(10a), Décima Época, Libro 40, marzo de 2017, tomo IV, p. 2639 (Registro $\mathrm{N}^{\circ}$ 2013812).

México, Semanario Judicial de la Federación y su Gaceta. Tesis II.3o.C.78 C, Semanario Judicial de la Federación y su Gaceta, Novena Época, tomo XXXI, marzo de 2010, p. 2928 (Registro N¹65071).

México, Semanario Judicial de la Federación y su Gaceta. Tesis II.3o.C.79 C, Semanario Judicial de la Federación y su Gaceta, Novena Época, tomo XXXI, marzo de 2010, p. 2959 (Registro N 165070). 
Reino Unido, C. v. C. (Minor: Abduction: Rights of Custody Abroad) [1989] 1 WLR 654 [cita INCADAT: HC/E/UKe 34].

Reino Unido, Re E. (Children) (Abduction: Custody Appeal) [2011] UKSC 27, [2012] 1 A.C. 144 [cita INCADAT: HC/E/UKe 1068].

Reino Unido, Re F. (Hague Convention: Child's Objections) [2006] FamCA 685, (2006) FLC 93-277; 36 Fam LR 183 [cita INCADAT: HC/E/AU 864].

Reino Unido, Re M. (A Minor) (Child Abduction) [1994] 1 FLR 390 [cita INCADAT: $\mathrm{HC} / \mathrm{E} / \mathrm{UKe} 56]$.

Reino Unido, Re S. (A Child) (Abduction: Rights of Custody) [2012] UKSC 10, [2012] 2 A.C. 257 [cita INCADAT: HC/E/UKe 1147].

Reino Unido, T.B. v. J.B. (Abduction: Grave Risk of Harm) [2001] 2 FLR 515 [cita INCADAT: HC/E/UKe 419]. 